\title{
Atomic-Scale Structural Characterization of Silver-Doped Phosphate-Based Glasses Prepared by Coacervation
}

\author{
B. A. Kyffin, D. M. Pickup, G. Mountjoy, F. Foroutan, I. Abrahams, and D. Carta*
}

Cite This: J. Phys. Chem. C 2021, 125, 12256-12268

Read Online

ABSTRACT: Phosphate-based glasses (PBGs) are traditionally prepared using the high-temperature melt-quenching (MQ) route or via the more recent sol-gel (SG) method that requires the use of organic solvents. The coacervation method represents an excellent inexpensive and green alternative to MQ and SG, being performed in aqueous solution and at room temperature. Coacervation is particularly applicable for the production of PBGs designed for biomedical applications because it allows for the inclusion of temperature-sensitive molecules and does not require the use of toxic solvents. Whereas the atomic structure of
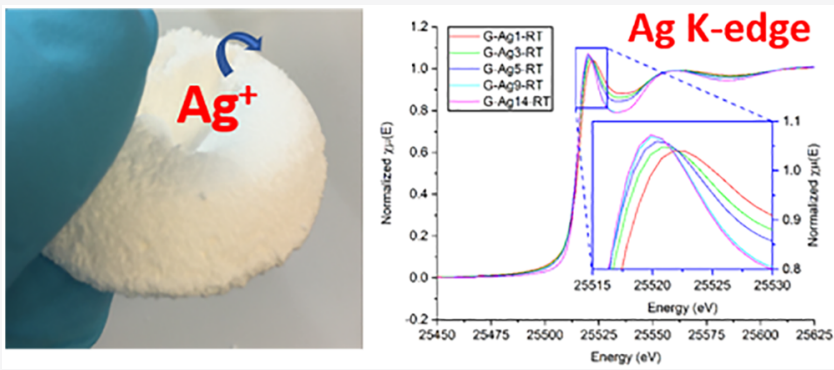
the MQ and SGPBGs is known, the atomic structure of those prepared via coacervation has yet to be investigated. In this study, a comprehensive advanced structural characterization has been performed on phosphate-based glasses in the system $\mathrm{P}_{2} \mathrm{O}_{5}-\mathrm{CaO}-\mathrm{Na}_{2} \mathrm{O}-\mathrm{Ag}_{2} \mathrm{O}\left(\mathrm{Ag}_{2} \mathrm{O}\right.$ mol \% = 0, 1, 3, 5, 9, and 14) prepared via the coacervation method. Glasses within this system should find application as bioresorbable biomaterials thanks to their ability to release bioactive ions in a controlled manner. In particular, they possess antibacterial properties, inferred by the release of $\mathrm{Ag}^{+}$over time. High-energy X-ray diffraction (HEXRD), ${ }^{31} \mathrm{P}$ and ${ }^{23} \mathrm{Na}$ solid-state magic-angle spinning nuclear magnetic resonance (MAS NMR), and X-ray absorption Spectroscopy (XAS) at the Ag K-edge were used to probe the atomic structure of the glasses after drying in vacuum and after calcination at $300{ }^{\circ} \mathrm{C}$. The length of the polyphosphate chains in the solid state appears to be independent of silver concentration; however, significant degradation of these chains is seen after calcination at $300{ }^{\circ} \mathrm{C}$. Atomic-scale characterisation results indicate that the structure of these glasses is akin to that of other silver-doped phosphate glasses prepared using the MQ and SG methods. This suggests that phosphate-based glasses prepared using milder and greener conditions may have similar chemical and physical properties such as solubility, biocompatibility, and antibacterial properties.

\section{INTRODUCTION}

Glasses, which possess regenerative properties for hard and soft tissues, have become an attractive option for biomedical applications. In particular, phosphate-based glasses (PBGs) have gained increasing attention within the biomedical field as a new generation of bioresorbable materials due to their ability to dissolve completely in a physiological environment. PBGs can be hydrolyzed into simple, non-toxic products (e.g. phosphate anions) without causing inflammatory reactions. This is advantageous over the commonly used bioresorbable polymers (e.g. polylactic and polyglycolic acids) whose degradation often results in crystalline fragments with heterogeneous chain lengths, which can lead to inflammation at the implantation site. ${ }^{2}$ It is this property that gives them an advantage over the widely investigated silicate-based glasses, which, despite their promising attributes, show very poor dissolution in bodily fluid, raising concerns about their longterm effects on health.

PBGs can be used for manufacturing bioresorbable implants with the additional function of acting as controlled delivery vehicles for therapeutic agents (e.g. antimicrobial ions, growth factors) and for simultaneous regeneration of hard and soft tissues without potential long-term complications. ${ }^{3}$ In particular, it has been shown that PBGs in the system $\mathrm{P}_{2} \mathrm{O}_{5}-\mathrm{CaO}-\mathrm{Na}_{2} \mathrm{O}$ are very promising materials for the regeneration of hard and soft tissues. ${ }^{4}$ It has also been shown that the addition of metallic ions, such as $\mathrm{Ag}^{+}, \mathrm{Cu}^{2+}$, and $\mathrm{Ga}^{3+}$, to the phosphate glass network can bestow antibacterial properties on the glasses. ${ }^{5-7}$

The traditional method for the production of phosphate glasses is the melt-quenching (MQ) process, which consists of melting oxides at high temperatures (typically $>1000{ }^{\circ} \mathrm{C}$ ), followed by rapid cooling to form a glass. ${ }^{8}$ The sol-gel (SG) method can be used as an alternative to MQ but requires the use of organic precursors/solvents and can be time consuming. Recently, the coacervation route has been proposed as an

Received: January 14, 2021

Revised: $\quad$ May 4, 2021

Published: May 26, 2021 
attractive alternative to the above methods, as it is a rapid, room-temperature, water-based, technique. ${ }^{7}$ The method is based on the formation of a colloidal polyphosphate system (coacervate) by the slow addition of $\mathrm{M}^{2+}$ ions (e.g. $\mathrm{M}=\mathrm{Ca}^{2+}$, $\mathrm{Co}^{2+}$, and $\mathrm{Ni}^{2+}$ ) to an aqueous sodium polyphosphate solution. $^{9-12}$ The wet viscous coacervate is then dried to remove the excess water to obtain a dry glass.

Several studies have been presented on PBGs prepared via MQ and to a lesser extent prepared via SG methods. ${ }^{13-17}$ However, very little work has been presented on PBGs formed via the coacervate route. The coacervate systems presented so far, such as $\mathrm{P}_{2} \mathrm{O}_{5}-\mathrm{ZnO}-\mathrm{Na}_{2} \mathrm{O}$ glasses, ${ }^{18,19} \mathrm{P}_{2} \mathrm{O}_{5}-\mathrm{CoO}-$ $\mathrm{Na}_{2} \mathrm{O},{ }^{9,20}$ and $\mathrm{P}_{2} \mathrm{O}_{5}-\mathrm{NiO}-\mathrm{Na}_{2} \mathrm{O}$ glass-ceramics, ${ }^{10}$ have not been designed for application as biomaterials. Recently, Pickup et al. $^{12}$ have synthesized a coacervate-based glass in the $\left(\mathrm{P}_{2} \mathrm{O}_{5}\right)_{0.50}-(\mathrm{CaO})_{0.50-x}-\left(\mathrm{Na}_{2} \mathrm{O}\right)_{x} \cdot y \mathrm{H}_{2} \mathrm{O}(x \approx 0.15$ and $y \approx 3)$ system to be used as a bioresorbable biomaterial. In particular, they have presented preliminary data on the doping of these systems with $\approx 1 \mathrm{~mol} \% \mathrm{Ag}^{+}$ions with promising data on the antibacterial activity against Pseudomonas aeruginosa. More recently, Kyffin et al. have presented a more extensive study on the synthesis and medium-long-range characterization of a series of PBGs in the systems $\mathrm{P}_{2} \mathrm{O}_{5}(44-48 \mathrm{~mol} \%)-\mathrm{CaO}$ $(35-41 \mathrm{~mol} \%)-\mathrm{Na}_{2} \mathrm{O}(6-12 \mathrm{~mol} \%)-\mathrm{Ag}_{2} \mathrm{O}(0,1,3,5,9$, and $14 \mathrm{~mol} \%)$ prepared by coacervation. This study has demonstrated that the addition of $\mathrm{Ag}^{+}$imparts antimicrobial properties against Staphylococcus aureus and that antibacterial properties increase with the $\mathrm{Ag}^{+}$content. These results suggest that the antibacterial activity is closely related to the release of silver ions during dissolution. In turn, ion release is strictly related to the atomic structure of the glasses. Therefore, advanced studies that shed light on the short- and mediumrange structures of doped glasses at the atomic level are important because they can contribute to the mechanistic understanding behind their antibacterial activity and biocompatibility, controlled mainly by dissolution rates and ion release, properties closely related to the atomic-scale structure of PBGs. $13,15,21$

Atomic-scale structural studies of PBGs prepared by MQ have been widely investigated. MQ glasses with compositions in the $\mathrm{P}_{2} \mathrm{O}_{5}(45-50 \mathrm{~mol} \%)-\mathrm{CaO}(8-40 \mathrm{~mol} \%)-\mathrm{Na}_{2} \mathrm{O}$ $(2-15 \mathrm{~mol} \%)$ system have shown great potential for applications such as dental repair and orthopedic implants. ${ }^{22,23}$ The addition of silver has been shown to impart antibacterial properties on MQ glasses, thanks to the slow release of $\mathrm{Ag}^{+}$ ions during dissolution. ${ }^{5,6}$

In this work, the advanced structural characterization of a series of antibacterial coacervate glasses in the system $\mathrm{P}_{2} \mathrm{O}_{5}-$ $\mathrm{CaO}-\mathrm{Na}_{2} \mathrm{O}-\mathrm{Ag}_{2} \mathrm{O}$ is presented. In contrast to MQ PBGs, no advanced comprehensive structural investigation of PBGs prepared by coacervation has been reported, only an extended X-ray absorption fine structure (EXAFS) study on the environment around $\mathrm{Ni}^{2+}$ and $\mathrm{Co}^{2+}$ in doped coacervate PBGs. ${ }^{20}$ Here, an advanced atomic-scale study on the systems $\mathrm{P}_{2} \mathrm{O}_{5}(44-48 \mathrm{~mol} \%)-\mathrm{CaO}(35-41 \mathrm{~mol} \%)-\mathrm{Na}_{2} \mathrm{O}(6-12$ mol \%) $-\mathrm{Ag}_{2} \mathrm{O}(0,1,3,5,9$, and $14 \mathrm{~mol} \%)$ prepared by coacervation is presented. A combination of magic-angle spinning solid-state nuclear magnetic resonance $\left({ }^{31} \mathrm{P}\right.$ and ${ }^{23} \mathrm{Na}$ MAS NMR) spectroscopy and synchrotron X-ray techniques, high-energy X-ray diffraction (HEXRD), and Xray absorption Spectroscopy (XAS) were used for the atomiclevel characterization of the PBGs as a function of silver content.
Solid-state MAS NMR was used to identify structural units and types of bonding within the glass network. ${ }^{31} \mathrm{P}$ MAS NMR allows the identification and quantification of the various $Q^{n}$ units that comprise the phosphate glass structure, where $Q$ represents the quaternary bonding of the phosphate tetrahedron and $n$ is the number of bridging oxygens per tetrahedron. ${ }^{23} \mathrm{Na}$ MAS NMR can be used to study the number and type of chemical sites that $\mathrm{Na}$ occupies.

XAS, which comprises extended X-ray absorption fine structure (EXAFS) and X-ray absorption near-edge structure (XANES), has been shown to be a powerful tool for the structural study of amorphous systems..$^{21,24-26}$ Both EXAFS and XANES are element-specific and sensitive to the local structure. EXAFS gives information about bond distances and coordination numbers of shells surrounding the absorbing atom, while XANES gives information on symmetry and the oxidation state of the absorbing atom. EXAFS and XANES have been used to characterize the environment surrounding antibacterial ions (such as $\mathrm{Ag}^{+}$and $\mathrm{Cu}^{2+}$ ) in $\mathrm{PBG}$ prepared via MQ. ${ }^{6,15,27}$ However, no information is available on the surrounding of such ions in PBGs prepared via coacervation.

HEXRD is the ideal technique to investigate the structure of amorphous materials. It provides information on interatomic distances and coordination numbers of the glass network via scattering patterns. HEXRD has also been used for the structural characterization of PBGs prepared via $\mathrm{MQ}$ and SG. ${ }^{6,14}$ Similarly, very little work has been reported on the HEXRD of coacervate-based PBGs. ${ }^{12}$ XAS and HEXRD can be considered complementary techniques since XAS is sensitive only to short-range order and HEXRD is sensitive to both short- and middle-range orders. ${ }^{28}$

By using these techniques in parallel, information on the structural arrangements of phosphate units, interatomic distances, oxidation states, and coordination numbers of coacervate-based PBGs were obtained along with the effect of silver doping on the structure.

\section{EXPERIMENTAL SECTION}

2.1. Synthesis. Glasses in the system $\mathrm{P}_{2} \mathrm{O}_{5}$ (44-48 mol \%) $-\mathrm{CaO}(35-41 \mathrm{~mol} \%)-\mathrm{Na}_{2} \mathrm{O}(6-12 \mathrm{~mol} \%)$ doped with various amounts of $\mathrm{Ag}_{2} \mathrm{O}(0,1,3,5,9$, and $14 \mathrm{~mol} \%)$ were prepared using the coacervation method, as recently described by Kyffin et al. ${ }^{7}$ Briefly, a $2 \mathrm{M}$ solution of calcium nitrate was mixed with an equal volume of a $4 \mathrm{M}$ aqueous solution of sodium polyphosphate. A phase separation occurred, and after complete addition, the upper layer (supernatant) was removed and the lower layer (coacervate) was allowed to settle for $24 \mathrm{~h}$. This was then dried for $48 \mathrm{~h}$ in a vacuum desiccator at room temperature before calcination at $300{ }^{\circ} \mathrm{C}$. Silver-doped glasses were produced by the addition of an appropriate volume of 2 $\mathrm{M}$ silver nitrate solution following the calcium nitrate. The volume of silver nitrate solution used was dependent on the desired mol \% of $\mathrm{Ag}_{2} \mathrm{O}$ in the final glass composition. The resultant vacuum-dried (at room temperature) and calcined glasses will be hereafter designated G-AgX-RT and G-AgX300 , respectively, where $X$ is the mol $\% \mathrm{Ag}_{2} \mathrm{O}$. Undoped glasses were named G-RT and G-300, respectively. Glass compositions were evaluated using energy-dispersive $\mathrm{X}$-ray (EDX) analysis on a JEOL JSM- 7100F system with an acceleration voltage set to $15 \mathrm{keV}$ and an emission current of $8 \mathrm{~mA}$. Glass compositions expressed in terms of mol \% are shown in $S 1$, SI. $^{7}$ 

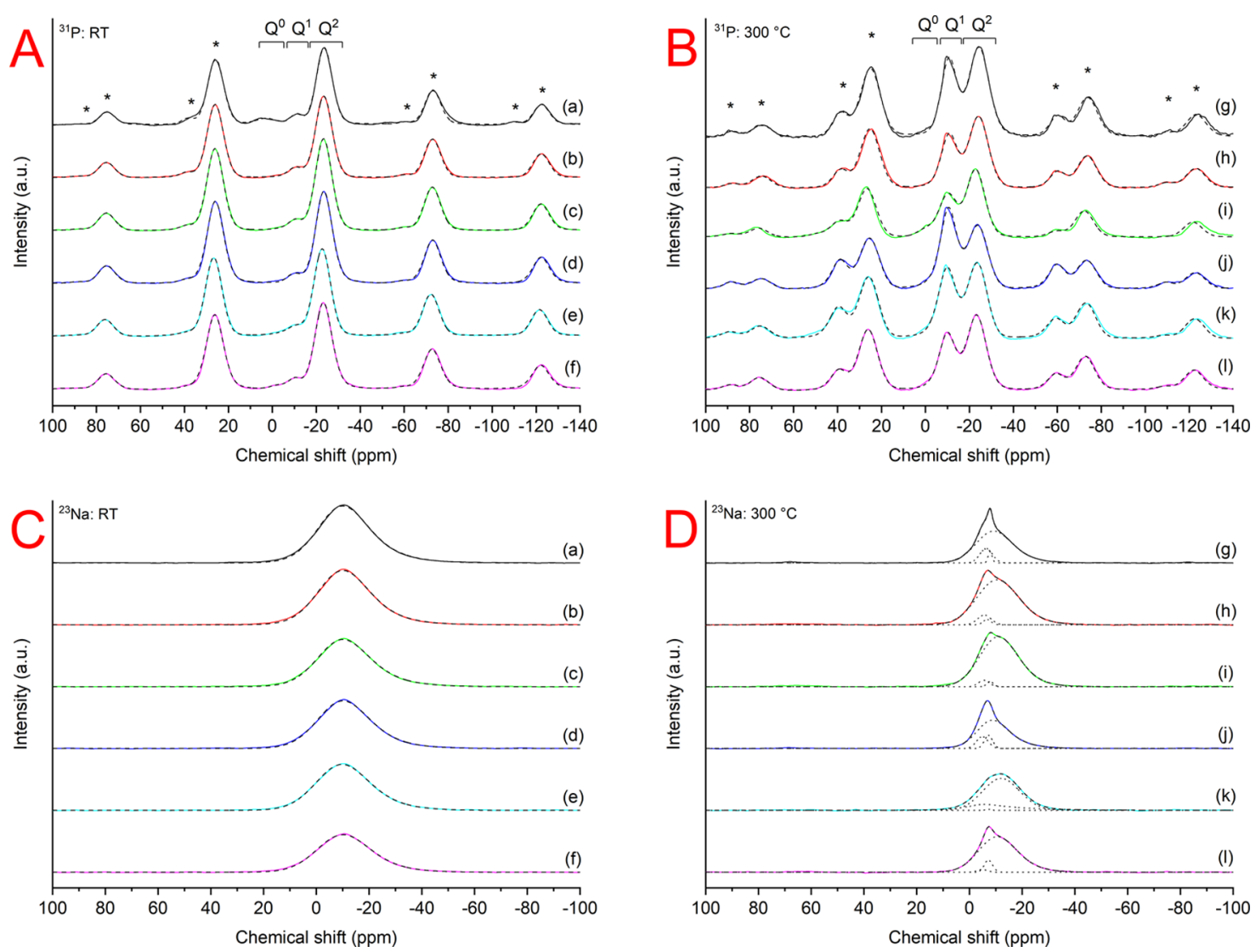

Figure 1. Solid-state MAS NMR spectra: (A) ${ }^{31} \mathrm{P}$ spectra of vacuum-dried glasses, (B) ${ }^{31} \mathrm{P}$ spectra of glasses calcined at $300{ }^{\circ} \mathrm{C}$, (C) ${ }^{23} \mathrm{Na}$ spectra of vacuum-dried glasses, and (D) ${ }^{23} \mathrm{Na}$ spectra of samples calcined at $300^{\circ} \mathrm{C}$. (a) G-RT, (b) G-Ag1-RT, (c) G-Ag3-RT, (d) G-Ag5-RT, (e) G-Ag9RT, (f) G-Ag14-RT, (g) G-300, (h) G-Ag1-300, (i) G-Ag3-300, (j) G-Ag5-300, (k) G-Ag9-300, and (l) G-Ag14-300. Asterisks indicate spinning side bands.

2.2. Characterization. ${ }^{31} \mathrm{P}$ MAS NMR was performed to investigate the network connectivity of the glasses using a Bruker Avance NEO $600 \mathrm{MHz}$ spectrometer with a spin rate of $12 \mathrm{kHz}$ and a $4 \mathrm{~mm} \mathrm{CP} / \mathrm{MAS} \mathrm{BB} 92-242.94 \mathrm{MHz}$ probe set at $242.938 \mathrm{MHz}$. Orthophosphoric acid (85\% solution) was used as a reference. Spectra were modeled using the programs DMFit $^{29}$ and NMRLSS. ${ }^{30}$ Chemical shift anisotropy parameters were calculated and refined using the Herzfeld-Berger method, ${ }^{31}$ with the use of the program HBA. ${ }^{32}$ The principal components $\left(\delta_{11}, \delta_{22}, \delta_{33}\right)$ of the chemical shift tensor were used to calculate the isotropic chemical shift $\left(\delta_{\text {iso }}\right)($ eq 1$)$ and were ordered according to the Haeberlen convention $\mid \delta_{33}-$ $\delta_{\text {iso }}|\geq| \delta_{11}-\delta_{\text {iso }}|\geq| \delta_{22}-\left.\delta_{\text {iso }}\right|^{33}$

$$
\delta_{\text {iso }}=\frac{\delta_{11}+\delta_{22}+\delta_{33}}{3}
$$

The chemical shift anisotropy $(\Delta \delta)$ and asymmetry $(\eta)$ parameters are given by

$$
\begin{aligned}
& \Delta \delta=\delta_{33}-\frac{\delta_{11}+\delta_{22}}{2} \\
& \eta=\frac{\delta_{22}-\delta_{11}}{\delta_{33}-\delta_{\text {iso }}}
\end{aligned}
$$

XAS data were collected on the B18 beamline at the Diamond Light Source, U.K. Samples with high uniformity were prepared by finely grinding all glass powders with poly(vinylpyrrolidone) (PVP) and pressing them into $13 \mathrm{~mm}$ diameter pellets. Data were collected at room temperature in a transmission mode at the Ag K-edge $(25514 \mathrm{eV})$. Each sample was measured a minimum of 12 times, with additional data collected for samples with lower silver contents to improve the signal-to-noise ratio. The energy scale was defined by assigning the maximum of the derivative of a silver foil spectrum, measured simultaneously with all samples. Data were also collected on a series of reference compounds $\left(\mathrm{Ag}_{3} \mathrm{PO}_{4}\right.$, $\mathrm{AgC}_{2} \mathrm{H}_{3} \mathrm{O}_{2}, \mathrm{AgCl}$, and $\mathrm{AgNO}_{3}$ ) as pellets prepared as above.

The data were processed using ATHENA and the EXAFS data fitted with ARTEMIS, both parts of the DEMETER package. ${ }^{34}$ Scattering paths were calculated using the ATOMS and FEFF6 programs, included within ARTEMIS. ${ }^{35,36}$ The structural parameters were obtained by nonlinear least-squares fitting in $k$ space with a $k^{3}$ weighting of the total experimental EXAFS spectra to emphasize the high-energy part of the spectrum. The fitting was carried out over the $k$-range of $1.2-$ $10 \AA^{-1}$, a range chosen to maximize real data without the significant introduction of noise. The amplitude reduction factor, $\mathrm{S}_{\mathrm{o}}^{2}$, was 0.9 for all fittings.

HEXRD data were collected on beamline I15-1 at the Diamond Light Source, U.K. The finely ground, dry powders were packed into $1.5 \mathrm{~mm}$ diameter borosilicate capillaries and mounted onto a multisample rack instrumental setup. The wavelength $(\lambda)$ was set at $0.161669 \AA$ and had been calibrated using a parametric refinement method at several distances. Measurements were taken between 0.07 and $37.5^{\circ}$ corresponding to a $Q$ range of $0.05-25 \AA^{-1}\left(Q_{\max }=4 \pi \sin \theta / \lambda\right)$. The data were processed using the GUDRUNX program, ${ }^{37}$ and the pair 
Table 1. Derived Spectral Parameters from Fitting ${ }^{31} \mathrm{P}$ MAS NMR Spectra. ${ }^{a} \mathrm{Q}^{n}$ Species Assignment, Chemical Shifts $\left(\delta_{\text {iso }}\right)$, Fractional Population of Each Environment $\left(\mathrm{P}_{\mathrm{Q}}{ }^{\mathrm{n}}\right)$, Principal Components of the Chemical Shift Tensor $\left(\delta_{11}, \delta_{22}, \delta_{33}\right)$, Chemical Shift Anisotropy $(\Delta \delta)$, and Asymmetry $(\eta)$.

\begin{tabular}{|c|c|c|c|c|c|c|c|c|}
\hline sample & environment & $\delta_{\text {iso }}(\mathrm{ppm})$ & ${ }^{b} P_{Q}{ }^{n}$ & $\delta_{11}$ & $\delta_{22}$ & $\delta_{33}$ & $\Delta \delta$ & $\eta$ \\
\hline \multirow[t]{3}{*}{ G-RT } & $Q^{0}$ & 2.9 & 0.04 & 2.9 & 2.9 & 2.9 & 0.0 & 0.0 \\
\hline & $Q^{1}$ & -10.8 & 0.05 & 46.6 & 46.6 & -125.7 & -172.3 & 0.0 \\
\hline & $Q^{2}$ & -23.6 & 0.91 & 42.0 & 42.0 & -154.9 & -197.0 & 0.0 \\
\hline \multirow[t]{3}{*}{ G-Ag1-RT } & $Q^{0}$ & & & & & & & \\
\hline & $Q^{1}$ & -10.4 & 0.08 & 41.4 & 41.4 & -114.0 & -155.4 & 0.0 \\
\hline & $Q^{2}$ & -23.5 & 0.92 & 43.5 & 43.5 & -157.4 & -200.9 & 0.0 \\
\hline \multirow[t]{3}{*}{ G-Ag3-RT } & $Q^{0}$ & & & & & & & \\
\hline & $Q^{1}$ & -10.2 & 0.07 & 41.0 & 41.0 & -112.5 & -153.5 & 0.0 \\
\hline & $Q^{2}$ & -23.4 & 0.93 & 74.1 & 10.9 & -155.1 & -197.6 & 0.5 \\
\hline \multirow[t]{3}{*}{ G-Ag5-RT } & $Q^{0}$ & & & & & & & \\
\hline & $Q^{1}$ & -9.6 & 0.03 & 70.7 & -9.7 & -89.9 & -120.4 & 1.0 \\
\hline & $Q^{2}$ & -23.5 & 0.97 & 74.2 & 10.1 & -154.8 & -197.0 & 0.5 \\
\hline \multirow[t]{3}{*}{ G-Ag9-RT } & $Q^{0}$ & & & & & & & \\
\hline & $Q^{1}$ & -10.7 & 0.10 & 64.8 & 2.0 & -99.1 & -132.5 & 0.7 \\
\hline & $Q^{2}$ & -22.7 & 0.90 & 75.6 & 11.7 & -155.5 & -199.2 & 0.5 \\
\hline \multirow[t]{3}{*}{ G-Ag14-RT } & $Q^{0}$ & -3.6 & 0.02 & 82.3 & -44.1 & -48.9 & -68.0 & 2.8 \\
\hline & $Q^{1}$ & -10.1 & 0.02 & 66.9 & -27.2 & -70.1 & -89.9 & 1.6 \\
\hline & $Q^{2}$ & -23.3 & 0.96 & 42.8 & 42.8 & -155.4 & -198.2 & 0.0 \\
\hline \multirow[t]{3}{*}{ G-300 } & $Q^{0}$ & & & & & & & \\
\hline & $Q^{1}$ & -10.7 & 0.31 & 68.5 & -5.9 & -94.7 & -126.1 & 0.9 \\
\hline & $Q^{2}$ & -24.4 & 0.69 & 70.1 & 6.0 & -149.2 & -187.2 & 0.5 \\
\hline \multirow[t]{3}{*}{ G-Ag1-300 } & $Q^{0}$ & & & & & & & \\
\hline & $Q^{1}$ & -10.8 & 0.32 & 73.8 & -6.8 & -99.5 & -133.0 & 0.9 \\
\hline & $Q^{2}$ & -24.2 & 0.68 & 41.3 & 41.3 & -155.1 & -196.4 & 0.0 \\
\hline \multirow[t]{3}{*}{ G-Ag3-300 } & $Q^{0}$ & -0.6 & 0.03 & 44.9 & 38.3 & -85.0 & -126.6 & 0.1 \\
\hline & $Q^{1}$ & -10.3 & 0.25 & 36.1 & 32.2 & -99.3 & -133.4 & 0.0 \\
\hline & $Q^{2}$ & -22.9 & 0.72 & 64.5 & 11.2 & -144.2 & -182.0 & 0.4 \\
\hline \multirow[t]{3}{*}{ G-Ag5-300 } & $Q^{0}$ & & & & & & & \\
\hline & $Q^{1}$ & -10.5 & 0.52 & 38.8 & 38.8 & -109.3 & -148.1 & 0.0 \\
\hline & $Q^{2}$ & -24.0 & 0.48 & 72.1 & 7.6 & -151.7 & -191.6 & 0.5 \\
\hline \multirow[t]{3}{*}{ G-Ag9-300 } & $Q^{0}$ & & & & & & & \\
\hline & $Q^{1}$ & -9.9 & 0.43 & 40.7 & 40.7 & -111.1 & -151.7 & 0.0 \\
\hline & $Q^{2}$ & -23.7 & 0.57 & 73.1 & 6.9 & -151.0 & -190.9 & 0.5 \\
\hline \multirow[t]{3}{*}{ G-Ag14-300 } & $Q^{0}$ & & & & & & & \\
\hline & $Q^{1}$ & -10.0 & 0.34 & 71.3 & -2.0 & -99.2 & -133.9 & 0.8 \\
\hline & $Q^{2}$ & -23.4 & 0.66 & 42.0 & 42.0 & -154.0 & -195.9 & 0.0 \\
\hline
\end{tabular}

${ }^{a}$ Estimated standard deviations are $<1 \% .{ }^{b}$ Calculated from simulation of the entire spectrum including side bands.

distribution functions (PDFs) were fitted with the use of NXFit_R $1 .^{38}$

\section{RESULTS AND DISCUSSION}

3.1. MAS NMR. Solid-state ${ }^{31} \mathrm{P}$ and ${ }^{23} \mathrm{Na}$ NMR spectra of all vacuum-dried and calcined glasses are shown in Figure 1A/ $\mathrm{B}, \mathrm{C} / \mathrm{D}$, respectively (solid lines). Spectra were fitted to obtain structural information, with the calculated spectra shown as dotted lines. Parameters derived from fitting the ${ }^{31} \mathrm{P}$ and ${ }^{23} \mathrm{Na}$ MAS NMR spectra are presented in Tables 1 and 2, respectively.

All ${ }^{31} \mathrm{P}$ spectra of the vacuum-dried glasses (Figure 1A) present a main resonance in the range of -22.7 to $-23.6 \mathrm{ppm}$ corresponding to $Q^{2}$ species and a weak resonance in the range of -9.6 to $-10.8 \mathrm{ppm}$ corresponding to $Q^{1}$ species. A very small resonance was only observed for G-RT and G-Ag14-RT corresponding to $Q^{0}$ species. $^{39}$

The ${ }^{31} \mathrm{P}$ MAS NMR fitting parameters of the vacuum-dried glasses reported in Table 1 confirm that they are composed mainly of $Q^{2}$ units, with the fractional population $\left(P_{Q}{ }^{n}\right)$ in the ranges of $0.90-0.97,0.02-0.10$, and $0.02-0.04$ for $Q^{2}, Q^{1}$, and $Q^{0}$, respectively. This indicates the presence of long polyphosphate chains with little formation of $Q^{0}$ or $Q^{1}$ species during synthesis. These data are consistent with results obtained from liquid-state ${ }^{31} \mathrm{P}$ NMR on the corresponding coacervates formed prior to vacuum drying, which showed that the chain lengths within the coacervates remained at ca. 25 units long, the same length as the original sodium polyphosphate precursor used for the synthesis. ${ }^{7}$ A phosphate chain consisting of 25 phosphate units results in a calculated 92:8 split of $Q^{2} / Q^{1}$, which closely matches the observed results in this work. Therefore, the hydrolytic breakdown of these polyphosphate chains appears to be minimal in the production of these glasses and after the vacuum drying process.

Some changes in the structure and length of the polyphosphate chains are observed after calcination at 300 ${ }^{\circ} \mathrm{C}$. $Q^{2}$ species are still predominant but their population is lower $\left(P_{Q}^{2}\right.$ in the range of $\left.0.50-0.70\right)$. There is a marked increase in the presence of $Q^{1}$ environments $\left(P_{Q}{ }^{1}\right.$ in the range of $0.31-0.50)$, but the presence of $Q^{0}$ species remains minimal. 
Table 2. Derived Spectral Parameters from Fitting ${ }^{23} \mathrm{Na}$ MAS NMR Spectra. Chemical Shifts $\left(\delta_{\text {iso }}\right)$, Fractional Population of Each Environment $(P)$ and Full Width at Half-Maximum (FWHM). Estimated Standard Deviations are $<1 \%$.

\begin{tabular}{lcccc}
\multicolumn{1}{c}{ sample } & environment & $\delta_{\text {iso }}(\mathrm{ppm})$ & $P$ & FWHM $(\mathrm{ppm})$ \\
G-Ag1-RT & 1 & -6.23 & 1.00 & 10.16 \\
G-RT & 1 & -6.19 & 1.00 & 9.76 \\
G-Ag3-RT & 1 & -6.21 & 1.00 & 10.14 \\
G-Ag5-RT & 1 & -6.22 & 1.00 & 10.30 \\
G-Ag9-RT & 1 & -6.01 & 1.00 & 10.77 \\
G-Ag14-RT & 1 & -6.22 & 1.00 & 10.87 \\
G-300 & 1 & -6.08 & 0.13 & 5.57 \\
& 2 & -7.63 & 0.03 & 1.48 \\
G-Ag1-300 & 3 & -7.67 & 0.84 & 12.73 \\
& 1 & -5.32 & 0.02 & 5.41 \\
& 2 & -6.45 & 0.06 & 5.89 \\
G-Ag3-300 & 3 & -8.89 & 0.92 & 15.34 \\
& 1 & -5.15 & 0.03 & 4.61 \\
G-Ag5-300 & 2 & -7.64 & 0.02 & 2.71 \\
& 3 & -9.42 & 0.95 & 14.11 \\
& 1 & -4.61 & 0.11 & 5.07 \\
G-Ag9-300 & 2 & -6.98 & 0.09 & 3.56 \\
& 3 & -7.33 & 0.80 & 10.11 \\
& 1 & -4.50 & 0.22 & 4.21 \\
G-Ag14-300 & 2 & -6.98 & 0.01 & 2.40 \\
& 3 & -10.99 & 0.77 & 15.51 \\
& 1 & -4.46 & 0.02 & 4.51 \\
& 2 & -6.90 & 0.06 & 3.38 \\
& 3 & -8.99 & 0.92 & 13.78 \\
\hline
\end{tabular}

The increase in $Q^{1}$ and reduction of $Q^{2}$ environments can be explained by the breakdown of the polyphosphate chains. It has been previously shown that long-chain polyphosphates undergo thermal breakdown at temperatures as low as $90{ }^{\circ} \mathrm{C}$, producing primarily pyrophosphates $\left(Q^{1}\right)$ and with continued treatment, orthophosphates $\left(Q^{0}\right) .{ }^{40}$ In addition, it has to be noted that the glasses presented in this work still contain considerable amounts of structural water, which is removed above $200{ }^{\circ} \mathrm{C}$. Due to a slow temperature ramp rate $\left(1{ }^{\circ} \mathrm{C} /\right.$ min) used for the calcination at $300{ }^{\circ} \mathrm{C}$, the structural water could be driven from the samples at even higher temperatures. The structural water may be involved in the hydrolytic attack of polyphosphate chains, which are extremely susceptible to nucleophilic attack; this could explain the reduction in network connectivity and the production of additional terminal phosphate groups.?

The extent of $\mathrm{P}-\mathrm{O}-\mathrm{P}$ cleavage in these samples varies, which results in differing $Q^{2} / Q^{1}$ ratios. In particular, G-Ag5-RT is in full agreement with the other uncalcined glasses, but after calcination, G-Ag5-300 shows a lower number of $Q^{2}$ groups compared to the rest of the series. This suggests that this specific composition has experienced a slightly increased degradation, perhaps during the thermal treatment.

It is difficult to determine from the ${ }^{31} \mathrm{P}$ MAS NMR data presented whether, post calcination, the glasses contain a mixture of pyrophosphates and cyclic metaphosphates or remain as shorter-chain polyphosphates. ${ }^{41}$ As there is no significant increase in and $Q^{0}$ and $Q^{3}$, it is believed that the glasses exist as short-chain polyphosphates, the chain length of which is significantly reduced compared to that prior calcination, with chains consisting of 4-7 phosphate units. Hydrolysis of the $\mathrm{P}-\mathrm{O}-\mathrm{P}$ bond can occur at any point on the chain as, although preferable at electron-deficient phosphorus environments, ${ }^{42}$ the chains are long enough so that differences in the electron density are minimal, and hence cleavage should be expected to occur at any point within the linear chain. Hydrolysis could also be affected by the local ions, and, as previously shown in ${ }^{31} \mathrm{P}$ MAS NMR experiments on phosphosilicates, the locations of $\mathrm{Ca}^{2+}$ and $\mathrm{Na}^{+}$ions in glasses appear to be random. ${ }^{43,44}$ It has been suggested that this is guided mainly by $\mathrm{Ca}^{2+}$ and $\mathrm{Na}^{+}$having very similar ionic radii. ${ }^{45}$

The ${ }^{23} \mathrm{Na}$ MAS NMR spectra of the vacuum-dried glasses (Figure 1C) show a broad peak in the range of -40 to $20 \mathrm{ppm}$ (centered at around $-6 \mathrm{ppm}$ ), indicating that the sodium lies in a wide range of environments. ${ }^{46}$ This broad peak splits into three discernible resonances after calcination at $300{ }^{\circ} \mathrm{C}$ (Figure $1 \mathrm{D})$. The dominant resonance $(-30$ to $10 \mathrm{ppm})$ remains broad and suggests that a considerable portion of the $\mathrm{Na}^{+}$ species remain in randomly distributed locations throughout the glass. The other smaller resonances ( 0 to $-10 \mathrm{ppm})$ are much sharper and suggest that some of the $\mathrm{Na}^{+}$locate themselves in preferential sites. As in the case of the ${ }^{31} \mathrm{P}$ MAS NMR data, there are no obvious compositional trends in the changes in $\mathrm{Na}^{+}$environment speciation and changes are likely to be linked to the extent of hydrolysis of the chains. It must be noted that, upon calcination, the changes in network
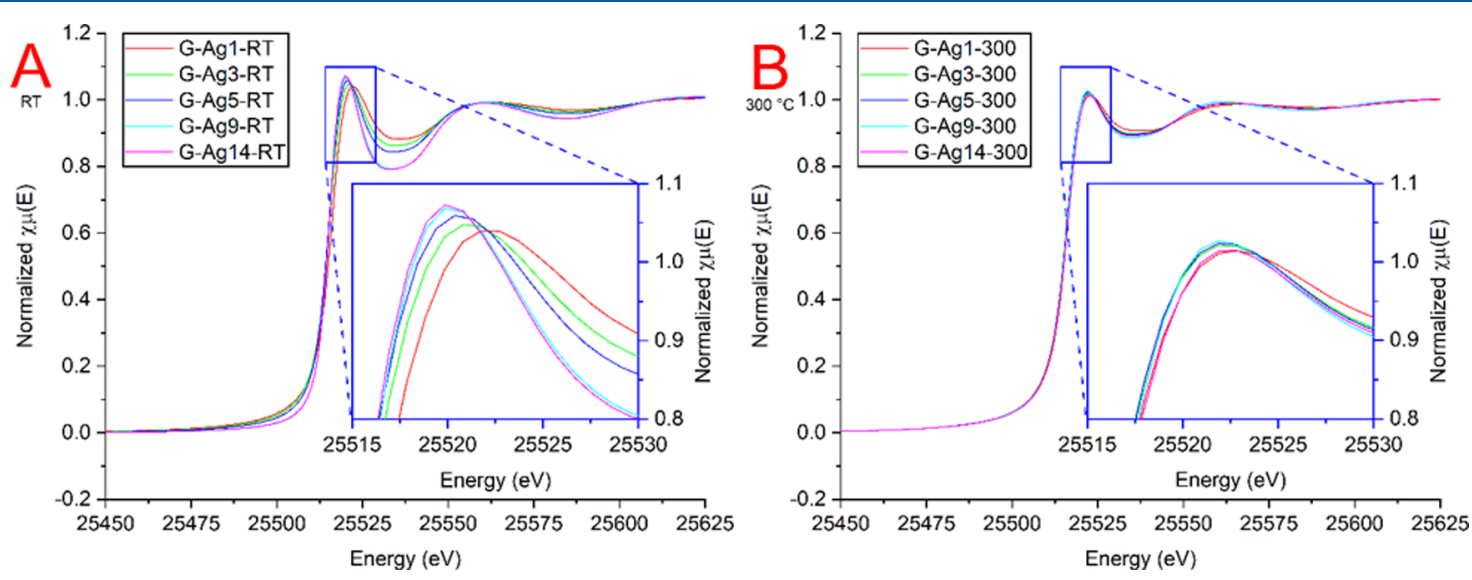

Figure 2. XANES spectra for (A) vacuum-dried glasses and (B) glasses calcined at $300{ }^{\circ} \mathrm{C}$. 
connectivity appear to be mostly independent of the silver content.

There is a significant lack of published ${ }^{23} \mathrm{Na}$ MAS NMR data on PBGs; however, the spectra observed in this study are very similar to those observed in the few ${ }^{23} \mathrm{Na}$ MAS NMR studies that have been conducted on MQ glasses. ${ }^{21,44,47-50}$ Broad ${ }^{23} \mathrm{Na}$ resonances of glasses slightly shift towards more negative values as the coordination number of sodium increases. ${ }^{43,47}$ In the data presented here, it is seen that the broad peak appears to shift slightly to a more negative value after calcination, with the narrower resonances remaining near the $\delta_{\text {iso }}$ of the broad peak seen in the spectra of the vacuum-dried glasses, if not shifting slightly downfield. It has also been seen in MQ glasses that resonances are shifted downfield with increasing sodium concentration. ${ }^{51}$ This is not seen in this study, probably due to the low concentrations of sodium in these samples compared to those in previously studied MQ glasses.

3.2. Ag K-Edge XANES. XANES analysis was performed to gain insights into the oxidation state of silver in all glasses. It also gives information about the coordination and chemical environment of the silver. XANES spectra of silver-doped samples vacuum dried and calcined are reported in Figure $2 \mathrm{~A}$ and $2 \mathrm{~B}$, respectively, with the spectra of reference materials given in Figure 3.

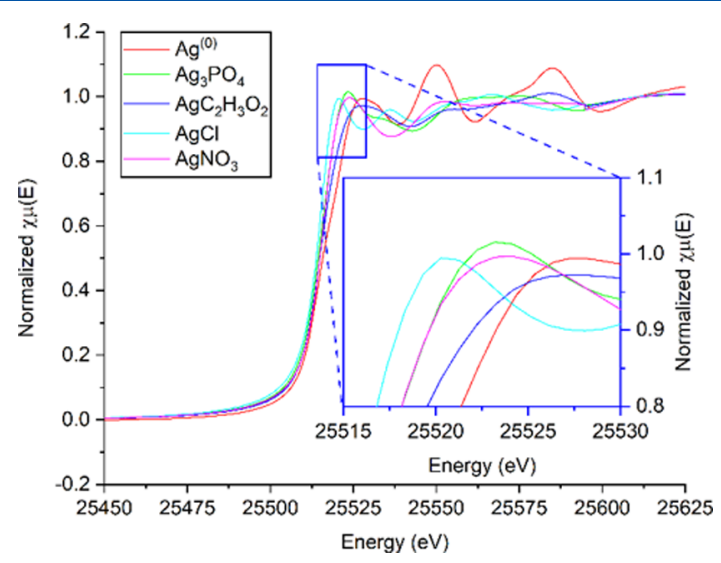

Figure 3. XANES spectra of reference materials: silver foil $\left(\mathrm{Ag}^{0}\right)$, $\mathrm{Ag}_{3} \mathrm{PO}_{4}, \mathrm{AgC}_{2} \mathrm{H}_{3} \mathrm{O}_{2}, \mathrm{AgCl}$, and $\mathrm{AgNO}_{3}$.

The value of $\mathrm{E}_{0}$ at the K-edge for all of the glasses was observed to be at $25516.5 \mathrm{eV}, \mathrm{ca}$. $+2.5 \mathrm{eV}$ above that of the $\mathrm{Ag}^{0}$ reference foils $(25514.0 \mathrm{eV})$. The variation in edge position between glasses is negligible. The energy required to excite electrons in positively charged ions is higher due to a contraction in the lowest unoccupied molecular orbitals (LUMOs), which in turn increases the excitation energy. From this, it can be concluded that the Ag species in the glasses have an oxidation state greater than 0 , as expected. When compared to the reference materials, $\mathrm{AgCl}$ also has a $\mathrm{K}$ edge at $25516.5 \mathrm{eV}$. The silver in $\mathrm{AgCl}$ has a formal charge of +1 and hence this would suggest that the oxidation state of silver in the glasses is also +1 , as expected. The oxidation state of $\mathrm{Ag}$ in the glasses is also confirmed by comparison of XANES spectra with those of a series of reference compounds (Figure 3). In particular, XANES spectra for all glasses are unlike that of the $\mathrm{Ag}^{0}$ foil, and are more comparable to that of $\mathrm{Ag}_{3} \mathrm{PO}_{4}$. This shows that the silver is not present as metallic silver/ nanoparticles and is incorporated into the network of the glass as $\mathrm{a}+1$ ion.
The edge step peak position provides additional information about the environment around the Ag. Reference foils of Ag have edge step peaks at $+14 \mathrm{eV}(25529 \mathrm{eV})$ relative to $\mathrm{E}_{0}$; this is confirmed by the value measured in this study. ${ }^{52,53}$ The step edge steepens and sharpens with increasing oxidation state and also with increasing number of coordinated oxygens. ${ }^{54}$ It can be seen clearly in the inset of Figure 2A that the edge step peak position for the vacuum-dried glasses shifts to a lower energy with increasing silver content, $+7.2 \mathrm{eV}(25522.2 \mathrm{eV})$ for GAg1-RT to $+4.8 \mathrm{eV}(25520.5 \mathrm{eV})$ for G-Ag14-RT. This suggests that the environment around $\mathrm{Ag}$ changes with increasing silver content and implies that the number of coordinated oxygens increases with silver content as well. This trend was also observed in previous studies on PBGs produced by $\mathrm{MQ}{ }^{55} \mathrm{~A}$ similar trend in the edge step peak position is observed for the calcined glasses (inset of Figure 2B); however, their distribution is tighter, indicative of less variation in the silver environments between these glasses.

3.3. Ag K-Edge EXAFS. EXAFS analysis was performed to investigate the environment around the silver ions in the glass network as a function of silver content and upon calcination. The Ag K-edge EXAFS $k^{3} \chi(k)$ spectra of vacuum-dried and calcined glasses are reported in Figure 4A,C, respectively. The respective corresponding pseudo-radial distribution functions (RDFs) are reported in Figure 4B,D. Values of $r$ have been phase-shifted with respect to the $\mathrm{Ag} \Leftrightarrow \mathrm{O}$ path. To obtain quantitative information, fitting of the EXAFS data was performed, and the calculated fits are shown in Figure 4 as dotted lines, with the fitting parameters summarized in Table 3. To maximize the amount of structural information, multiple measurements were taken of each sample, which were later combined to increase the signal-to-noise ratio.

EXAFS $k^{3} \chi(k)$ spectra for the vacuum-dried coacervate glasses and their corresponding RDFs vary little between the glasses, which suggests that the environment surrounding the silver center does not change dramatically with silver content. However, it must be noted that the amplitude of the EXAFS oscillations and the intensity of their corresponding peaks in the RDFs increase with silver content. The amplitudes of EXAFS oscillations are directly correlated to the number of scatterers and therefore are directly linked to the coordination number and the atomic number of the scattering atom. In these samples, the scattering atom in the first shell (oxygen) is not changed and therefore it can be assumed that the increase in amplitude is caused by an increasing oxygen coordination number to the silver center, as silver content increases within the glasses. This observation is consistent with the sharpening of the edge step peak data (Figure 2A).

In all samples, vacuum-dried and calcined, the frequency of EXAFS oscillations does not change significantly with silver content, resulting in very similar RDFs. All RDFs (vacuumdried and calcined) show the presence of one prominent peak at $c$ a. $2.35 \AA$, a weak peak at ca. $3.51 \AA$, and a broad peak at $c a$. $3.80 \AA$. The first peak is attributed to the $\mathrm{Ag} \Leftrightarrow \mathrm{O}$ scattering path and has been fitted using $\mathrm{Ag}_{3} \mathrm{PO}_{4}$ as a model calculated via FEFF. ${ }^{56}$ In all glasses, $\mathrm{Ag}-\mathrm{O}$ distances are around 2.35/ $2.36 \AA$, in agreement with $\mathrm{Ag}-\mathrm{O}$ distances previously found in MQ silver-doped glasses. ${ }^{57,58}$

The second, lower-amplitude, peak at ca. $3.51 \AA$ has been attributed to a combination of two scattering paths for $\mathrm{Ag} \Leftrightarrow \mathrm{P}$ (Ag $\Leftrightarrow \mathrm{P}_{1}$ and $\mathrm{Ag} \Leftrightarrow \mathrm{P}_{2}$ ). These paths were obtained using FEFF calculations from the crystal structure of $\mathrm{Ag}_{2} \mathrm{HPO}_{4}{ }^{59}$ This calculation produces four $\mathrm{Ag} \Leftrightarrow \mathrm{P}$ single scattering paths 

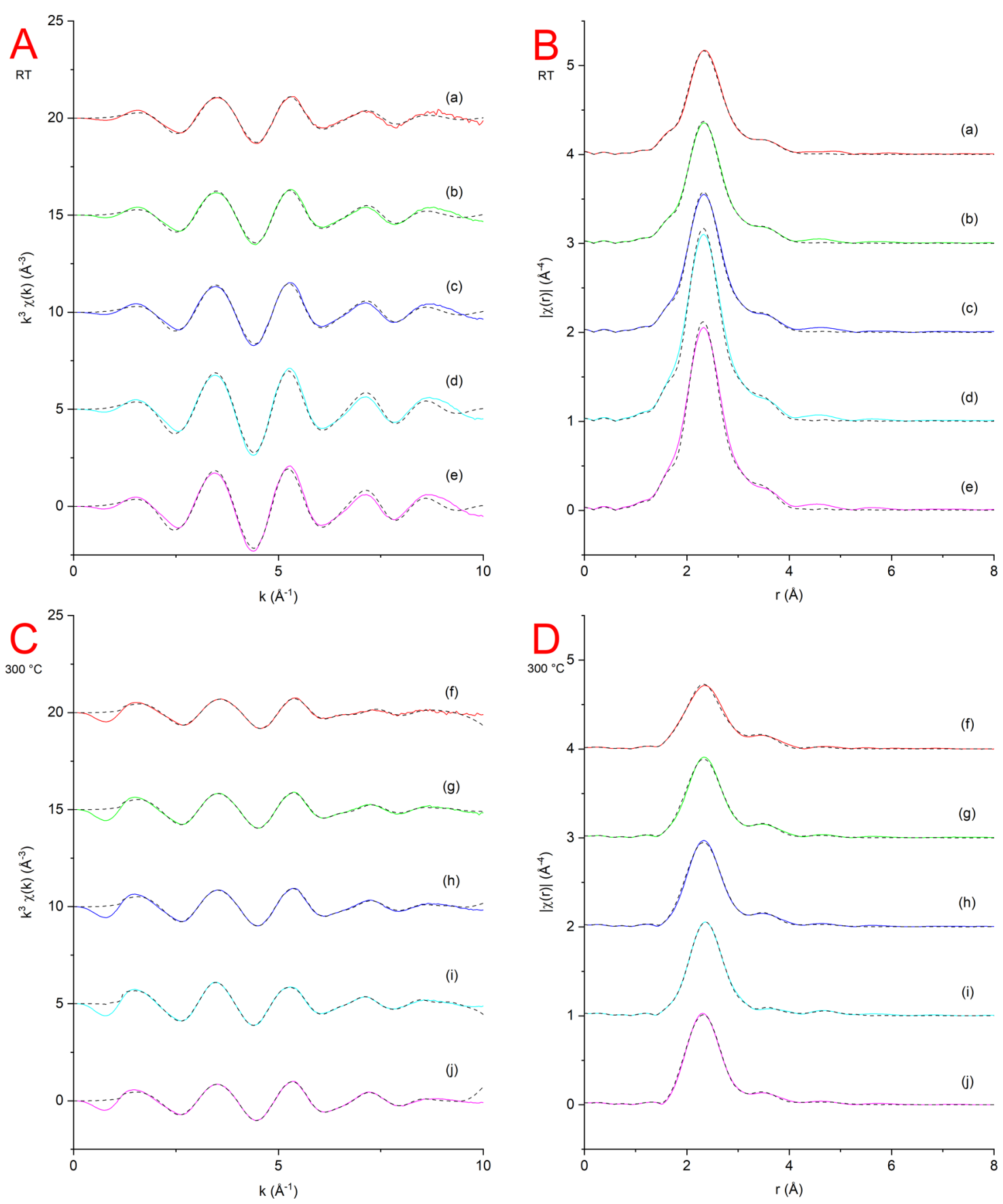

Figure 4. (A) Fitted $k^{3} \chi(k)$ EXAFS spectra; (B) RDFs, $\chi(\mathrm{r}) \mathrm{l}$, at the Ag K-edge of (a) G-Ag1-RT, (b) G-Ag3-RT, (c) G-Ag5-RT, (d) G-Ag9-RT, and (e) G-Ag14-RT; (C) EXAFS $k^{3} \chi(k)$ spectra; and (D) RDFs, l $\chi(\mathrm{r})$ I, at the Ag K-edge of (f) G-Ag1-300, (g) G-Ag3-300, (h) G-Ag5-300, (i) GAg9-300, and (j) G-Ag14-300. Experimental data (solid line) and fit (dashed line).

at lengths of $3.24,3.82,4.39$, and $4.90 \AA$. The inclusion of all combinations of these scattering paths was investigated, and it was concluded that the combination of the scattering paths at 3.24 and $3.82 \AA$ provided the best model for the data. Similar findings were found by Silva et al. ${ }^{20}$ within coacervate-derived cobalt- and nickel-doped phosphate glasses.

The degeneracy of the $\mathrm{Ag} \Leftrightarrow \mathrm{P}$ paths calculated by FEFF is 2; however, due to the inclusion of both paths to produce a reliable model of the system, the degeneracy of both paths was set to 1 . This finding suggests that the second shell consists of ca. 2 phosphorus atoms at a distance between 3.3 and $3.8 \AA$ from the Ag atom. This finding is supported by other XAS studies into silver-doped glasses, such as that by Sipr et al. ${ }^{60}$ on
MQ silver-doped borate glasses, who suggested that silver can form two radially smeared coordination shells, the first containing ca. 4 oxygens and the second containing 4 or more boron atoms. It is plausible that in the coacervate-derived glasses presented here, such radially smeared shells are also present, with phosphorus atoms constituting the second shell. The silver is located between two phosphorus atoms, suggesting that it is between two end-chain $Q^{1}$ environments or possibly between two $Q^{2}$ units.

The only difference between vacuum-dried glasses and calcined ones seems to be the coordination number around silver within the first $\mathrm{Ag}-\mathrm{O}$ shell. In the vacuum-dried samples, the oxygen coordination number within the first $\mathrm{Ag}-\mathrm{O}$ shell 
Table 3. Structural Parameters Obtained by Fitting the Experimental EXAFS Spectra ${ }^{a}$

\begin{tabular}{|c|c|c|c|c|c|}
\hline sample & shell & $\mathrm{r} / \AA ̊$ & $\mathrm{~N}$ & $\sigma^{2} / \AA^{2}\left(\times 10^{-2}\right)$ & $R$-factor $\left(\times 10^{-3}\right)$ \\
\hline \multirow[t]{3}{*}{ G-Ag1-RT } & $\mathrm{Ag}-\mathrm{O}$ & $2.35( \pm 0.01)$ & $4.1( \pm 0.51)$ & $2.05( \pm 0.26)$ & 4.04 \\
\hline & $\mathrm{Ag}-\mathrm{P}_{1}$ & $3.30( \pm 0.04)$ & $1.0( \pm 0.12)$ & $2.04( \pm 0.76)$ & \\
\hline & $\mathrm{Ag}-\mathrm{P}_{2}$ & $3.81( \pm 0.06)$ & $1.0( \pm 0.12)$ & $1.97( \pm 1.15)$ & \\
\hline \multirow[t]{3}{*}{ G-Ag3-RT } & $\mathrm{Ag}-\mathrm{O}$ & $2.35( \pm 0.01)$ & $4.4( \pm 0.27)$ & $1.90( \pm 0.12)$ & 2.10 \\
\hline & $\mathrm{Ag}-\mathrm{P}_{1}$ & $3.30( \pm 0.02)$ & $1.0( \pm 0.06)$ & $1.81( \pm 0.35)$ & \\
\hline & $\mathrm{Ag}-\mathrm{P}_{2}$ & $3.79( \pm 0.03)$ & $1.0( \pm 0.06)$ & $1.84( \pm 0.55)$ & \\
\hline \multirow[t]{3}{*}{ G-Ag5-RT } & $\mathrm{Ag}-\mathrm{O}$ & $2.36( \pm 0.01)$ & $5.0( \pm 0.25)$ & $1.76( \pm 0.10)$ & 1.73 \\
\hline & $\mathrm{Ag}-\mathrm{P}_{1}$ & $3.30( \pm 0.02)$ & $1.0( \pm 0.05)$ & $1.17( \pm 0.27)$ & \\
\hline & $\mathrm{Ag}-\mathrm{P}_{2}$ & $3.79( \pm 0.03)$ & $1.0( \pm 0.05)$ & $1.59( \pm 0.44)$ & \\
\hline \multirow[t]{3}{*}{ G-Ag9-RT } & $\mathrm{Ag}-\mathrm{O}$ & $2.36( \pm 0.01)$ & $6.3( \pm 0.29)$ & $1.76( \pm 0.09)$ & 2.78 \\
\hline & $\mathrm{Ag}-\mathrm{P}_{1}$ & $3.30( \pm 0.01)$ & $1.0( \pm 0.05)$ & $1.25( \pm 0.23)$ & \\
\hline & $\mathrm{Ag}-\mathrm{P}_{2}$ & $3.82( \pm 0.03)$ & $1.0( \pm 0.05)$ & $1.72( \pm 0.49)$ & \\
\hline \multirow[t]{3}{*}{ G-Ag14-RT } & $\mathrm{Ag}-\mathrm{O}$ & $2.36( \pm 0.01)$ & $6.3( \pm 0.29)$ & $1.77( \pm 0.09)$ & 2.76 \\
\hline & $\mathrm{Ag}-\mathrm{P}_{1}$ & $3.30( \pm 0.01)$ & $1.0( \pm 0.05)$ & $1.57( \pm 0.23)$ & \\
\hline & $\mathrm{Ag}-\mathrm{P}_{2}$ & $3.81( \pm 0.03)$ & $1.0( \pm 0.05)$ & $1.20( \pm 0.47)$ & \\
\hline \multirow[t]{3}{*}{ G-Ag1-300 } & $\mathrm{Ag}-\mathrm{O}$ & $2.32( \pm 0.01)$ & $4.0( \pm 0.76)$ & $2.64( \pm 0.23)$ & 5.60 \\
\hline & $\mathrm{Ag}-\mathrm{P}_{1}$ & $3.24( \pm 0.02)$ & $1.0( \pm 0.19)$ & $2.06( \pm 0.47)$ & \\
\hline & $\mathrm{Ag}-\mathrm{P}_{2}$ & $3.73( \pm 0.04)$ & $1.0( \pm 0.19)$ & $1.91( \pm 0.70)$ & \\
\hline \multirow[t]{3}{*}{ G-Ag3-300 } & $\mathrm{Ag}-\mathrm{O}$ & $2.33( \pm 0.01)$ & $4.5( \pm 0.43)$ & $2.50( \pm 0.11)$ & 3.20 \\
\hline & $\mathrm{Ag}-\mathrm{P}_{1}$ & $3.26( \pm 0.02)$ & $1.0( \pm 0.10)$ & $2.34( \pm 0.34)$ & \\
\hline & $\mathrm{Ag}-\mathrm{P}_{2}$ & $3.75( \pm 0.02)$ & $1.0( \pm 0.10)$ & $1.78( \pm 0.37)$ & \\
\hline \multirow[t]{3}{*}{ G-Ag5-300 } & $\mathrm{Ag}-\mathrm{O}$ & $2.33( \pm 0.01)$ & $4.3( \pm 0.38)$ & $2.29( \pm 0.09)$ & 2.40 \\
\hline & $\mathrm{Ag}-\mathrm{P}_{1}$ & $3.26( \pm 0.02)$ & $1.0( \pm 0.08)$ & $2.39( \pm 0.34)$ & \\
\hline & $\mathrm{Ag}-\mathrm{P}_{2}$ & $3.75( \pm 0.02)$ & $1.0( \pm 0.08)$ & $1.71( \pm 0.33)$ & \\
\hline \multirow[t]{3}{*}{ G-Ag9-300 } & $\mathrm{Ag}-\mathrm{O}$ & $2.37( \pm 0.01)$ & $4.5( \pm 0.47)$ & $2.23( \pm 0.15)$ & 0.99 \\
\hline & $\mathrm{Ag}-\mathrm{P}_{1}$ & $3.40( \pm 0.02)$ & $1.0( \pm 0.07)$ & $2.18( \pm 0.39)$ & \\
\hline & $\mathrm{Ag}-\mathrm{P}_{2}$ & $3.76( \pm 0.04)$ & $1.0( \pm 0.07)$ & $1.85( \pm 0.40)$ & \\
\hline \multirow[t]{3}{*}{ G-Ag14-300 } & $\mathrm{Ag}-\mathrm{O}$ & $2.33( \pm 0.01)$ & $4.0( \pm 0.28)$ & $1.90( \pm 0.08)$ & 1.37 \\
\hline & $\mathrm{Ag}-\mathrm{P}_{1}$ & $3.29( \pm 0.02)$ & $1.0( \pm 0.07)$ & $2.35( \pm 0.34)$ & \\
\hline & $\mathrm{Ag}-\mathrm{P}_{2}$ & $3.74( \pm 0.02)$ & $1.0( \pm 0.07)$ & $1.72( \pm 0.32)$ & \\
\hline
\end{tabular}

increases with increasing silver content, starting at 4.1 in GAg1-RT and increasing to 6.3 for G-Ag14-RT. Results suggest that the silver in the vacuum-dried samples is located in a tetrahedral site at low silver content but adopts an octahedral arrangement as the silver content increases. ${ }^{27}$ This is in agreement with the XANES results, which also suggest that the coordination number of silver in the vacuum-dried glasses increases with silver content.

In the calcined samples, the oxygen coordination number within the first $\mathrm{Ag}-\mathrm{O}$ shell remains constant, around 4, indicating that the silver is tetrahedrally coordinated and the silver concentration has little effect on this. This agrees with XANES results, which also suggest that the coordination number of silver does not change for the calcined glasses with silver content unlike in the vacuum-dried glasses. This is confirmed by the consistency in the edge step peak position of the calcined glasses. The change in the edge step peak position from vacuum-dried to calcined glasses, which is noticeable for the high silver content glasses, is consistent with a structural change upon calcination. Comparison with Ag K-edge XANES spectra in the literature suggests that this change can be associated with a shift from a more "nitrate-like" environment in the uncalcined glasses to a more "phosphate-like" environment upon calcination. ${ }^{61,62}$

The coordination number of the higher silver content glasses appears to drop to 4 upon calcination; however, it is likely that a distorted $\mathrm{Ag}$ environment, similar to those seen in $\mathrm{Ag}_{3} \mathrm{PO}_{4}$ and $\mathrm{AgBaP}_{3} \mathrm{O}_{9}$, is present in the calcined glasses, with coordination numbers of 5 or 6 . However, due to their very distorted nature, fittings of these environments often only capture the shortest, most defined atomic distances, as the longer bonds give evanescent oscillations with large DebyeWaller factors. ${ }^{62}$ An increase in coordination number would normally increase the bond length, ${ }^{63}$ but with the inability to represent these longer bonds sufficiently, only the bond lengths associated with the shortest $\mathrm{Ag}-\mathrm{O}$ bonds are observed.

3.4. High-Energy X-ray Diffraction. HEXRD is a powerful tool to investigate the structural characteristics of glasses, which can be difficult to measure by other methods. HEXRD provides information on local order such as local bonding lengths and coordination numbers, as well as enabling the study of more remote atomic pairs. ${ }^{64,65}$ HEXRD data for all glasses are presented in Figure 5. Q-space interference functions, $S(Q)$, and pair distribution functions, $T(r)$, together with their fits, are shown in Figure $5 \mathrm{~A} / \mathrm{C}$ and $\mathrm{B} / \mathrm{D}$, respectively. HEXRD data for the vacuum-dried glasses are presented in Figure 5A,B and those for the glasses calcined at $300{ }^{\circ} \mathrm{C}$ are presented in Figure 5C,D. Structural parameters obtained from fitting are reported in Table 4. Densities of doped samples used for fittings are presented in Table S2, SI. The glasses have been modeled using interatomic distances obtained from crystallographic data. Although bond lengths should be similar to those in crystallographic data, it has been seen that bond lengths differ between glasses doped with differing network modifiers. This is clear when studying the $\mathrm{P}-$ $\mathrm{O}$ bond lengths for both terminal and bridging oxygen species, 

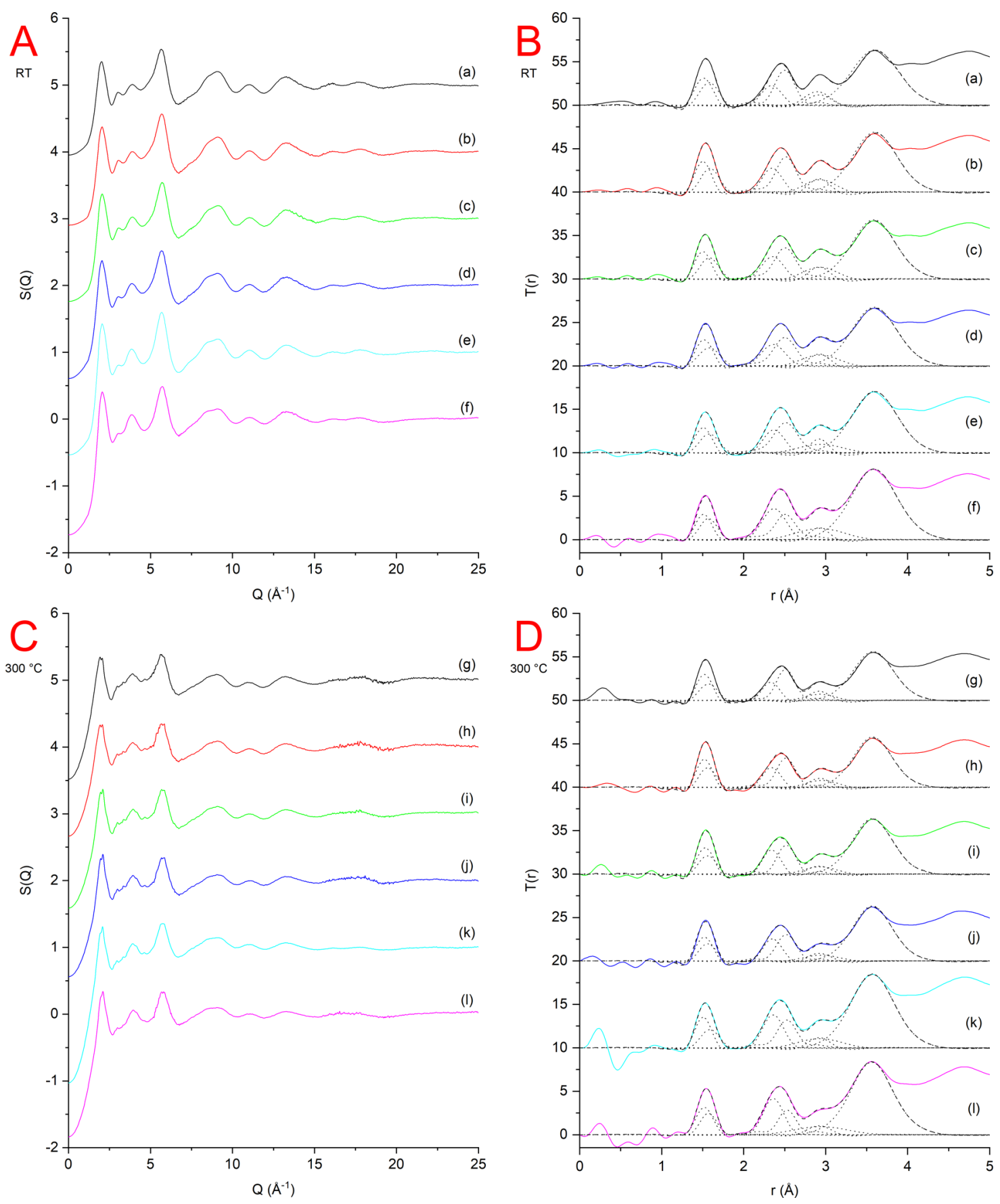

Figure 5. X-ray diffraction data for the vacuum-dried glasses (A and B) and the calcined glasses (C and D). (A and C) Q-space structure factor, S(Q), (B and D) pair distribution functions, T(r). (a) G-RT, (b) G-Ag1-RT, (c) G-Ag3-RT, (d) G-Ag5-RT, (e) G-Ag9-RT, (f) G-Ag14-RT, (g) G300, (h) G-Ag1-300, (i) G-Ag3-300, (j) G-Ag5-300, (k) G-Ag9-300, and (l) G-Ag14-300. Experimental data (solid line), fit (dashed line), and partial functions (dotted).

as the depletion of the valence electrons from the cation to the phosphate network changes the ionicity of the bonds and therefore their lengths. Bond distances can also be affected by phosphate chain length and cation coordination number. ${ }^{66}$

There are no significant differences in the short-range pair correlations between the structure of vacuum-dried and calcined glasses or between glasses containing different silver loadings. In all glasses, vacuum-dried and calcined, the first peak in the pair distribution function $T(r)$ occurs at $c a .1 .55 \AA$ and it is due to two partially overlapping $\mathrm{P}-\mathrm{O}$ atomic distances. The shorter $\mathrm{P}-\mathrm{O}$, at ca. $1.51 \AA$, is attributed to the interatomic distance between phosphorus and a non-bridging oxygen (P-NBO); the slightly longer path, at ca. $1.59 \AA$, involves a phosphorus and a bridging oxygen species $(\mathrm{P}-\mathrm{BO})$. This is consistent with the bond lengths presented in previous studies on MQ and SG PBGs. ${ }^{14-16,66-68}$ The coordination numbers of these two peaks also give confirmation of the chain length. In the vacuum-dried glasses, the coordination numbers of both the $\mathrm{P}-\mathrm{NBO}$ and $\mathrm{P}-\mathrm{BO}$ bonds are close to 2 , with the $\mathrm{P}-\mathrm{NBO}$ being slightly higher than that of the $\mathrm{P}-\mathrm{BO}$. Each phosphorus is bonded to 4 oxygens, so the combination of these two coordination numbers is close to 4 , as expected. The 
Table 4. Structural Parameters Obtained from the XPDF Fittings of Vacuum-Dried and Calcined Glasses ${ }^{a, b}$

\begin{tabular}{|c|c|c|c|c|c|c|c|c|c|}
\hline sample & correlation & $r / \AA$ & $\mathrm{N}$ & $\sigma / \AA$ & sample & correlation & $r / \AA$ & $\mathrm{N}$ & $\sigma / \AA$ \\
\hline \multirow[t]{6}{*}{ G-RT } & $\mathrm{P}-\mathrm{NBO}$ & 1.51 & 2.06 & 0.05 & \multirow[t]{6}{*}{ G-300 } & $\mathrm{P}-\mathrm{NBO}$ & 1.52 & 2.27 & 0.02 \\
\hline & $\mathrm{P}-\mathrm{BO}$ & 1.58 & 1.96 & 0.07 & & $\mathrm{P}-\mathrm{BO}$ & 1.57 & 1.81 & 0.07 \\
\hline & $\mathrm{M}-\mathrm{O}$ & 2.34 & 3.92 & 0.09 & & $\mathrm{M}-\mathrm{O}$ & 2.33 & 3.94 & 0.07 \\
\hline & $\mathrm{O} \cdots \mathrm{O}$ & 2.51 & 4.32 & 0.08 & & $\mathrm{O} \cdots \mathrm{O}$ & 2.51 & 3.96 & 0.08 \\
\hline & $\mathrm{P} \cdots \mathrm{P}$ & 2.92 & 1.98 & 0.12 & & $\mathrm{P} \cdots \mathrm{P}$ & 2.92 & 1.81 & 0.09 \\
\hline & $\mathrm{M} \cdots \mathrm{P}$ & 2.91 & 1.79 & 0.14 & & $\mathrm{M} \cdots \mathrm{P}$ & 2.93 & 1.56 & 0.19 \\
\hline \multirow{5}{*}{ G-Ag1-RT } & $\mathrm{P}-\mathrm{BO}$ & 1.59 & 1.95 & 0.07 & \multirow{5}{*}{ G-Ag1-300 } & $\mathrm{P}-\mathrm{BO}$ & 1.56 & 1.76 & 0.04 \\
\hline & $\mathrm{M}-\mathrm{O}$ & 2.35 & 3.84 & 0.10 & & $\mathrm{M}-\mathrm{O}$ & 2.34 & 3.73 & 0.08 \\
\hline & $\mathrm{O} \cdots \mathrm{O}$ & 2.51 & 4.25 & 0.09 & & $\mathrm{O} \cdots \mathrm{O}$ & 2.52 & 3.48 & 0.08 \\
\hline & $\mathrm{P} \cdots \mathrm{P}$ & 2.92 & 1.93 & 0.09 & & $\mathrm{P} \cdots \mathrm{P}$ & 2.93 & 1.72 & 0.10 \\
\hline & $\mathrm{M} \cdots \mathrm{P}$ & 2.93 & 2.04 & 0.20 & & $\mathrm{M} \cdots \mathrm{P}$ & 2.95 & 1.49 & 0.20 \\
\hline \multirow[t]{5}{*}{ G-Ag3-RT } & $\mathrm{P}-\mathrm{NBO}$ & 1.50 & 2.05 & 0.03 & \multirow[t]{5}{*}{ G-Ag3-300 } & $\mathrm{P}-\mathrm{NBO}$ & 1.53 & 2.28 & 0.01 \\
\hline & $\mathrm{P}-\mathrm{BO}$ & 1.58 & 1.96 & 0.07 & & $\mathrm{P}-\mathrm{BO}$ & 1.56 & 1.80 & 0.05 \\
\hline & $\mathrm{O} \cdots \mathrm{O}$ & 2.51 & 4.41 & 0.10 & & $\mathrm{O} \cdots \mathrm{O}$ & 2.52 & 3.55 & 0.06 \\
\hline & $\mathrm{P} \cdots \mathrm{P}$ & 2.92 & 1.95 & 0.09 & & $\mathrm{P} \cdots \mathrm{P}$ & 2.92 & 1.80 & 0.12 \\
\hline & $\mathrm{M} \cdots \mathrm{P}$ & 2.93 & 2.05 & 0.22 & & $\mathrm{M} \cdots \mathrm{P}$ & 2.93 & 1.50 & 0.22 \\
\hline \multirow[t]{6}{*}{ G-Ag5-RT } & $\mathrm{P}-\mathrm{NBO}$ & 1.52 & 2.04 & 0.02 & \multirow[t]{6}{*}{ G-Ag5-300 } & $\mathrm{P}-\mathrm{NBO}$ & 1.52 & 2.29 & 0.01 \\
\hline & $\mathrm{P}-\mathrm{BO}$ & 1.58 & 1.95 & 0.09 & & $\mathrm{P}-\mathrm{BO}$ & 1.56 & 1.80 & 0.04 \\
\hline & $\mathrm{M}-\mathrm{O}$ & 2.36 & 3.84 & 0.13 & & $\mathrm{M}-\mathrm{O}$ & 2.35 & 3.84 & 0.09 \\
\hline & $\mathrm{O} \cdots \mathrm{O}$ & 2.50 & 4.11 & 0.10 & & $\mathrm{O} \cdots \mathrm{O}$ & 2.52 & 3.52 & 0.08 \\
\hline & $\mathrm{P} \cdots \mathrm{P}$ & 2.92 & 1.96 & 0.09 & & $\mathrm{P} \cdots \mathrm{P}$ & 2.92 & 1.78 & 0.11 \\
\hline & $\mathrm{M} \cdots \mathrm{P}$ & 2.93 & 2.03 & 0.24 & & $\mathrm{M} \cdots \mathrm{P}$ & 2.95 & 1.32 & 0.24 \\
\hline \multirow[t]{4}{*}{ G-Ag9-RT } & $\mathrm{P}-\mathrm{NBO}$ & 1.51 & 2.04 & 0.04 & \multirow[t]{4}{*}{ G-Ag9-300 } & $\mathrm{P}-\mathrm{NBO}$ & 1.51 & 2.32 & 0.02 \\
\hline & $\mathrm{P}-\mathrm{BO}$ & 1.58 & 1.95 & 0.08 & & $\mathrm{P}-\mathrm{BO}$ & 1.59 & 1.71 & 0.06 \\
\hline & $\mathrm{M}-\mathrm{O}$ & 2.37 & 3.67 & 0.11 & & $\mathrm{M}-\mathrm{O}$ & 2.36 & 3.79 & 0.10 \\
\hline & $\mathrm{O} \cdots \mathrm{O}$ & 2.51 & 3.96 & 0.11 & & $\mathrm{O} \cdots \mathrm{O}$ & 2.53 & 3.51 & 0.07 \\
\hline \multirow[t]{6}{*}{ G-Ag14-RT } & $\mathrm{P}-\mathrm{NBO}$ & 1.51 & 2.05 & 0.02 & \multirow[t]{6}{*}{ G-Ag14-300 } & $\mathrm{P}-\mathrm{NBO}$ & 1.52 & 2.29 & 0.04 \\
\hline & $\mathrm{P}-\mathrm{BO}$ & 1.57 & 1.96 & 0.05 & & $\mathrm{P}-\mathrm{BO}$ & 1.57 & 1.79 & 0.03 \\
\hline & $\mathrm{M}-\mathrm{O}$ & 2.37 & 3.95 & 0.13 & & $\mathrm{M}-\mathrm{O}$ & 2.36 & 3.66 & 0.10 \\
\hline & $\mathrm{O} \cdots \mathrm{O}$ & 2.51 & 3.89 & 0.08 & & $\mathrm{O} \cdots \mathrm{O}$ & 2.53 & 3.39 & 0.06 \\
\hline & $\mathrm{P} \cdots \mathrm{P}$ & 2.92 & 1.91 & 0.06 & & $\mathrm{P} \cdots \mathrm{P}$ & 2.92 & 1.77 & 0.11 \\
\hline & $\mathrm{M} \cdots \mathrm{P}$ & 2.93 & 2.01 & 0.32 & & $M \cdots P$ & 2.94 & 1.50 & 0.35 \\
\hline
\end{tabular}

$a_{r}$ is the atomic separation, $\mathrm{N}$ is the coordination number, and $\sigma$ is the disorder parameter. $\mathrm{NBO}$ represents nonbridging oxygen species, BO represents bridging oxygen species, and $\mathrm{M}$ represents the generic metal species calculated as a mix of $\mathrm{Na}, \mathrm{Ca}$, and $\mathrm{Ag}$ dependent on composition. ${ }^{b}$ Errors: $r \pm 0.02 \AA, \mathrm{N} \pm 20 \%$, and $\sigma \pm 0.01 \AA$.

higher coordination number of $\mathrm{P}-\mathrm{NBO}$ over that of $\mathrm{P}-\mathrm{BO}$ is due to the terminal $Q^{1}$ groups at the end of long polyphosphate chains of a finite length. These coordination numbers indicate a chain length of ca. 25 units, in agreement with the NMR results. ${ }^{67}$ In the calcined glasses, the difference between $\mathrm{P}-\mathrm{NBO}$ and $\mathrm{P}-\mathrm{BO}$ coordination numbers is much larger due to the higher prevalence of terminal $Q^{1}$ species. This again is consistent with the NMR results and suggests that the chains undergo significant hydrolytic breakdown during calcination.

A second broad peak is observed in all glasses, vacuum-dried and calcined, at ca. $2.4 \AA$. Previous studies have shown that $\mathrm{Na}-\mathrm{O}$ and $\mathrm{Ca}-\mathrm{O}$ have similar bond lengths at 2.33 and 2.34 $\AA$, respectively, in MQPBGs. ${ }^{67}$ Therefore, both $\mathrm{Na}$ and Ca are usually indicated in the fitting as one generic metal ion, $\mathrm{M}$; this has shown to be an effective way in which to accurately model PBGs. ${ }^{12}$ For this reason, the same merging procedure has been performed in the modeling process for this study, with the additional inclusion of $\mathrm{Ag}-\mathrm{O}$, which has a similar bond length of $c a .2 .35 \AA$. In addition, the $\mathrm{O}-\mathrm{O}$ interatomic distance at $2.50 \AA$ must be considered.

Therefore, the second peak at ca. $2.4 \AA$ is the result of the overlap of the interatomic distances of $\mathrm{M}-\mathrm{O}$, at $2.34 \AA(\mathrm{M}=$ $\mathrm{Ca}, \mathrm{Na}$ and $\mathrm{Ag}$ ), and $\mathrm{O}-\mathrm{O}$, at $2.50 \AA$. The intensity of the peak at ca. $2.4 \AA$ is seen to grow steadily with increasing silver content as well as a slight shift toward a longer $\mathrm{M}-\mathrm{O}$ distance due to the increasing contribution provided by $\mathrm{Ag}-\mathrm{O}$ scattering. The third peak at ca. $3.0 \AA$ can be attributed to the overlap of $\mathrm{M}-\mathrm{P}$ and $\mathrm{P}-\mathrm{P}$ distances. The $M \Leftrightarrow P$ path shows low amplitude and a large disorder parameter, which makes $M \Leftrightarrow P$ correlations the least well defined of the correlations reported, and so we will not discuss them in detail. It is interesting to note that the coordination number of the $\mathrm{P}$ $\Leftrightarrow \mathrm{P}$ path is close to that of the $\mathrm{P}-\mathrm{BO}$. This is to be expected as the interatomic distances between the phosphorus atoms are controlled heavily by the bridging oxygens. ${ }^{12}$ It has to be noted that fittings including $\mathrm{Ag} \Leftrightarrow \mathrm{Ag}$ interactions were attempted considering $\mathrm{Ag}-\mathrm{Ag}$ distances of 2.5-3 $\AA$; however, no reasonable fitting could be achieved through this method. 


\section{CONCLUSIONS}

The atomic-scale structure of a series of vacuum-dried and calcined at $300{ }^{\circ} \mathrm{C}$ coacervate-derived glasses in the $\mathrm{P}_{2} \mathrm{O}_{5}-$ $\mathrm{CaO}-\mathrm{Na}_{2} \mathrm{O}-\mathrm{Ag}_{2} \mathrm{O}$ system $\left(\mathrm{Ag}_{2} \mathrm{O}\right.$ contents $1,3,5,9$, and 14 mol \%) was investigated using a series of advanced complementary techniques $\left({ }^{31} \mathrm{P}\right.$ and ${ }^{23} \mathrm{Na}$ MAS NMR, XAS and HEXRD). ${ }^{23} \mathrm{Na}$ MAS NMR reveals that before calcination, $\mathrm{Na}^{+}$exists in a wide distribution of sites; however, after calcination at $300{ }^{\circ} \mathrm{C}$, a significant proportion of the $\mathrm{Na}^{+}$ moves to a preferential site. The degree of this rearrangement does not appear to be significantly correlated to silver content. ${ }^{31} \mathrm{P}$ MAS NMR analysis shows that after calcination the polyphosphate chains degrade significantly, and this could be due to hydrolysis reactions from structural water remaining in the glasses after vacuum drying. The degradation of the chains does not appear to be significantly correlated to the silver content of the glasses.

XANES analysis has shown that in all glasses studied, silver has an oxidation state of +1 with no formation of metallic aggregates. EXAFS analysis has shown that the coordination number around silver ions in the first $\mathrm{Ag}-\mathrm{O}$ shell increases with increasing $\mathrm{Ag}$ content from 4 to 6 , prior to calcination, but postcalcination remains around 4. HEXRD analysis has shown that interatomic distances, along with coordination numbers of phosphate species in the coacervate-derived glasses, are similar to those observed in glasses of similar compositions prepared by sol-gel or melt quenching. It also provides an insight into how metal ions are situated within the network.

This study has shown that silver-doped phosphate-based glasses prepared via the coacervate route are similar in atomic structure to those prepared via sol-gel and melt quenching. Thus, the coacervate method offers a green and economical route to synthesizing PBGs equivalent in structure to those made by sol-gel and melt quenching.

\section{ASSOCIATED CONTENT}

\section{s) Supporting Information}

The Supporting Information is available free of charge at https://pubs.acs.org/doi/10.1021/acs.jpcc.1c00363.

Compositional data presented as oxide mol \% is shown in Table S1; and density of the glasses studied is shown in Table S2 (PDF)

\section{AUTHOR INFORMATION}

\section{Corresponding Author}

D. Carta - Department of Chemistry, University of Surrey, GU2 7XH Guildford, U.K.; ๑ orcid.org/0000-0002-43444061; Phone: +44 (0)1483 689587; Email: d.carta@ surrey.ac.uk

\section{Authors}

B. A. Kyffin - Department of Chemistry, University of Surrey, GU2 7XH Guildford, U.K.

D. M. Pickup - School of Physical Sciences, University of Kent, Canterbury, Kent CT2 7NH, U.K.

G. Mountjoy - School of Physical Sciences, University of Kent, Canterbury, Kent CT2 7NH, U.K.; 이이.orcid.org/0000-00026495-2006

F. Foroutan - Department of Chemistry, University of Surrey, GU2 7XH Guildford, U.K.
I. Abrahams - Department of Chemistry, Queen Mary University of London, London E1 4NS, U.K.; (1) orcid.org/ 0000-0002-8606-6056

Complete contact information is available at:

https://pubs.acs.org/10.1021/acs.jpcc.1c00363

\section{Notes}

The authors declare no competing financial interest.

\section{ACKNOWLEDGMENTS}

The authors would like to acknowledge the EPSRC (grant EP/ P033636/1) and Royal Society (grant RSG/R1/180191) for providing the funding to conduct this study. The authors would also like to thank Diamond Light Source, UK, for beamtime (XAS proposal SP18595 and HEXRD proposals EE18923, EE21525, and CY26578). The authors also specially thank Dr S. Parry and Dr G. Cibin, beamline B18, for assistance with the XAS data collection and Dr D. Keeble and Dr G. Cutts, beamline I15-1, for assistance in performing the HEXRD experiments. Finally, the authors would like to thank Dr Harold Toms at the Queen Mary University of London for help in performing MAS NMR experiments.

\section{REFERENCES}

(1) Momeni, A.; Filiaggi, M. J. Degradation and Hemostatic Properties of Polyphosphate Coacervates. Acta Biomater. 2016, 41, $328-341$.

(2) Brannigan, R. P.; Dove, A. P. Synthesis, Properties and Biomedical Applications of Hydrolytically Degradable Materials Based on Aliphatic Polyesters and Polycarbonates. Biomater. Sci. 2017, 5, 9.

(3) Ahmed, I.; Lewis, M.; Olsen, I.; Knowles, J. C. Phosphate Glasses for Tissue Engineering: Part 1. Processing and Characterisation of a Ternary-Based $\mathrm{P}_{2} \mathrm{O}_{5}-\mathrm{CaO}-\mathrm{Na}_{2} \mathrm{O}$ Glass System. Biomaterials 2004, 25, 491-499.

(4) Tilocca, A.; Cormack, A. N.; De Leeuw, N. H. The Structure of Bioactive Silicate Glasses: New Insight from Molecular Dynamics Simulations. Chem. Mater. 2007, 19, 95-103.

(5) Ahmed, I.; Ready, D.; Wilson, M.; Knowles, J. C. C. Antimicrobial Effect of Silver-Doped Phosphate-Based Glasses. J. Biomed. Mater. Res., Part A 2006, 79, 618-626.

(6) Valappil, S. P.; Pickup, D. M.; Carroll, D. L.; Hope, C. K.; Pratten, J.; Newport, R. J.; Smith, M. E.; Wilson, M.; Knowles, J. C. Effect of Silver Content on the Structure and Antibacterial Activity of Silver-Doped Phosphate-Based Glasses. Antimicrob. Agents Chemother. 2007, 51, 4453-4461.

(7) Kyffin, B. A.; Foroutan, F.; Raja, F. N. S.; Martin, R. A.; Pickup, D. M.; Taylor, S. E.; Carta, D. Antibacterial Silver-Doped PhosphateBased Glasses Prepared by Coacervation. J. Mater. Chem. B 2019, 7, 7744-7755.

(8) Ciceo Lucacel, R.; Hulpus, A. O.; Simon, V.; Ardelean, I. Structural Characterization of Phosphate Glasses Doped with Silver. J. Non-Cryst. Solids 2009, 355, 425-429.

(9) Silva, M. A. P.; Franco, D. F.; Brandão, A. R.; Barud, H.; Dias Filho, F. A.; Ribeiro, S. J. L.; Messaddeq, Y.; De Oliveira, L. F. C. Spectroscopic Studies on Glassy $\mathrm{Ni}(\mathrm{II})$ and $\mathrm{Co}(\mathrm{II})$ Polyphosphate Coacervates. Mater. Chem. Phys. 2010, 124, 547-551.

(10) Franco, D. F.; Manzani, D.; Barud, H. S.; Antonio, S. G.; de Oliveira, L. F. C.; Silva, M. A. P.; Ribeiro, S. J. L.; Nalin, M. Structural Investigation of Nickel Polyphosphate Coacervate Glass-Ceramics. RSC Adv. 2016, 6, 91150-91156.

(11) Luczak, O.; Ledoux, A.; Gomez, F.; Vast, P.; Miyajima, T. Physical Properties of Polyphosphate Coacervates as Glass Precursors Suitable for Coating Process, in the System $\mathrm{Na}_{2} \mathrm{O}-\mathrm{CaO}-\mathrm{P}_{2} \mathrm{O}_{5}$. Phosphorus Res. Bull. 1997, 7, 23-28. 
(12) Pickup, D. M.; Newport, R. J.; Barney, E. R.; Kim, J. Y.; Valappil, S. P.; Knowles, J. C. Characterisation of Phosphate Coacervates for Potential Biomedical Applications. J. Biomater. Appl. 2014, 28, 1226-1234.

(13) Carta, D.; Pickup, D. M.; Knowles, J. C.; Ahmed, I.; Smith, M. E.; Newport, R. J. A Structural Study of Sol-Gel and Melt-Quenched Phosphate-Based Glasses. J. Non-Cryst. Solids 2007, 353, 1759-1765. (14) Pickup, D. M.; Guerry, P.; Moss, R. M.; Knowles, J. C.; Smith, M. E.; Newport, R. J. New Sol-Gel Synthesis of a $(\mathrm{CaO})_{0.3}\left(\mathrm{Na}_{2} \mathrm{O}\right)_{0.2}\left(\mathrm{P}_{2} \mathrm{O}_{5}\right)_{0.5}$ Bioresorbable Glass and Its Structural Characterisation. J. Mater. Chem. 2007, 17, 4777-4784.

(15) Pickup, D. M.; Ahmed, I.; FitzGerald, V.; Moss, R. M.; Wetherall, K. M.; Knowles, J. C.; Smith, M. E.; Newport, R. J. X-Ray Absorption Spectroscopy and High-Energy XRD Study of the Local Environment of Copper in Antibacterial Copper-Releasing Degradable Phosphate Glasses. J. Non-Cryst. Solids 2006, 352, 3080-3087.

(16) Moss, R. M.; Abou Neel, E. A.; Pickup, D. M.; Twyman, H. L.; Martin, R. A.; Henson, M. D.; Barney, E. R.; Hannon, A. C.; Knowles, J. C.; Newport, R. J. The Effect of Zinc and Titanium on the Structure of Calcium-Sodium Phosphate Based Glass. J. Non-Cryst. Solids 2010, $356,1319-1324$.

(17) Musinu, A.; Piccaluga, G.; Pinna, G.; Vlaic, G.; Narducci, D.; Pizzini, S. Coordination of Zinc and Copper in Phosphate Glasses by EXAFS. J. Non-Cryst. Solids 1991, 136, 198-204.

(18) Palavit, G.; Montagne, L.; Delaval, R. Preparation of ZincSodium Phosphate Glass Precursors by Coacervation. J. Non-Cryst. Solids 1995, 189, 277-282.

(19) Willot, G.; Gomez, F.; Vast, P.; Andries, V.; Martines, M.; Messaddeq, Y.; Poulain, M. Preparation of Zinc Sodium Polyphosphates Glasses from Coacervates Precursors. Characterisation of the Obtained Glasses, and Their Applications. C. R. Chim. 2002, 5, 899-906.

(20) Silva, M. A. P.; Franco, D. F.; De Oliveira, L. F. C. New Insight on the Structural Trends of Polyphosphate Coacervation Processes. J. Phys. Chem. A 2008, 112, 5385-5389.

(21) Martin, R. A.; Twyman, H. L.; Rees, G. J.; Barney, E. R.; Moss, R. M.; Smith, J. M.; Hill, R. G.; Cibin, G.; Charpentier, T.; Smith, M. E.; et al. An Examination of the Calcium and Strontium Site Distribution in Bioactive Glasses through Isomorphic Neutron Diffraction, X-Ray Diffraction, EXAFS and Multinuclear Solid State NMR. J. Mater. Chem. 2012, 22, 22212-22223.

(22) Salih, V.; Franks, K.; James, M.; Hastings, G. W.; Knowles, J. C.; Olsen, I. Development of Soluble Glasses for Biomedical Use Part II: The Biological Response of Human Osteoblast Cell Lines to Phosphate-Based Soluble Glasses. J. Mater. Sci.: Mater. Med. 2000, 11, 615-620.

(23) Bitar, M.; Salih, V.; Mudera, V.; Knowles, J. C.; Lewis, M. P. Soluble Phosphate Glasses: In Vitro Studies Using Human Cells of Hard and Soft Tissue Origin. Biomaterials 2004, 25, 2283-2292.

(24) Dalba, G.; Fornasini, P.; Rocca, F.; Bernieri, E.; Burattini, E.; Mobilio, S. EXAFS Studies of Silver Ion Coordination in Silver Borate Glasses. J. Non-Cryst. Solids 1987, 91, 153-164.

(25) Dalba, G.; Fornasini, P.; Kuzmin, A.; Monti, F.; Sanson, A.; Sipr, O.; Rocca, F. XANES and EXAFS Modelling of Configurational Disorder in Silver Borate Glasses. Phys. Scr. 2005, 2005, No. 149.

(26) Barney, E. R.; Hannon, A. C.; Senkov, O. N.; Scott, J. M.; Miracle, D. B.; Moss, R. M. A Neutron and X-Ray Diffraction Study of Ca-Mg-Cu Metallic Glasses. Intermetallics 2011, 19, 860-870.

(27) Ahmed, I.; Abou Neel, E. A.; Valappil, S. P.; Nazhat, S. N.; Pickup, D. M.; Carta, D.; Carroll, D. L.; Newport, R. J.; Smith, M. E.; Knowles, J. C. The Structure and Properties of Silver-Doped Phosphate-Based Glasses. J. Mater. Sci. 2007, 42, 9827-9835.

(28) Carta, D.; Corrias, A.; Navarra, G. A Total X-Ray Scattering Study of $\mathrm{MnFe}_{2} \mathrm{O}_{4}$ Nanoparticles Dispersed in a Silica Aerogel Matrix. J. Non-Cryst. Solids 2011, 357, 2600-2603.

(29) Massiot, D.; Fayon, F.; Capron, M.; King, I.; Le Calvé, S.; Alonso, B.; Durand, J.-O. O.; Bujoli, B.; Gan, Z.; Hoatson, G. Modelling One- and Two-Dimensional Solid-State NMR Spectra. Magn. Reson. Chem. 2002, 40, 70-76.
(30) Abrahams, I. In NMRLSS - Nuclear Magnetic Resonance Least Squares Refinement for Solids, Version 1.5; Queen Mary University of London, 2003.

(31) Herzfeld, J.; Berger, A. E. Sideband Intensities in NMR Spectra of Samples Spinning at the Magic Angle. J. Chem. Phys. 1980, 73, 6021-6030.

(32) Eichele, K. HBA, version 1.7.5; Universität Tübingen, 2015.

(33) Haeberlen, U. High Resolution Nmr in Solids Selective Averaging; version 1.5; Academic Press, 1976.

(34) Ravel, B.; Newville, M. ATHENA, ARTEMIS, HEPHAESTUS: Data Analysis for X-Ray Absorption Spectroscopy Using IFEFFIT. J. Synchrotron Radiat. 2005, 12, 537-541.

(35) Ravel, B. ATOMS: Crystallography for the X-Ray Absorption Spectroscopist. J. Synchrotron Radiat. 2001, 8, 314-316.

(36) Zabinsky, S. I.; Rehr, J. J.; Ankudinov, A.; Albers, R. C.; Eller, M. J. Multiple-Scattering Calculations of $\mathrm{x}$-Ray-Absorption Spectra. Phys. Rev. B 1995, 52, 2995-3009.

(37) Soper, A. K. GudrunN and GudrunX: Programs for Correcting Raw Neutron and X-Ray Diffraction Data to Differential Scattering Cross Section. Rutherford Appleton Laboratory Technical Report RAL-TR2011-013; 2011.

(38) Pickup, D.; Moss, R.; Newport, R. NXFit: A Program for Simultaneously Fitting X-Ray and Neutron Diffraction Pair-Distribution Functions to Provide Optimized Structural Parameters. J. Appl. Crystallogr. 2014, 47, 1790-1796.

(39) Franco, D. F.; Barud, H. S.; Santagneli, S.; Lamarca, R. S.; Santos, B. F.; Silva, M. A. P.; de Oliveira, L. F. C.; Ribeiro, S. J. L.; Nalin, M. Preparation and Structural Characterization of Sodium Polyphosphate Coacervate as a Precursor for Optical Materials. Mater. Chem. Phys. 2016, 180, 114-121.

(40) Casas, J. M.; García, M. P.; Sanz, M.; Cacho, F.; Pérez, J. ${ }^{31}$ P NMR Spectroscopic Studies of the Influence of the Environment in the Degradation Process of the Graham's Salt. Ceram. Int. 2010, 36, $39-46$.

(41) Döhler, F.; Mandlule, A.; Van Wüllen, L.; Friedrich, M.; Brauer, D. S. ${ }^{31} \mathrm{P}$ NMR Characterisation of Phosphate Fragments during Dissolution of Calcium Sodium Phosphate Glasses. J. Mater. Chem. B 2015, 3, 1125-1134.

(42) Strauss, U. P.; Treitler, T. L. Degradation of Polyphosphates in Solution. I. Kinetics and Mechanism of the Hydrolysis at Branching Points in Polyphosphate Chains. J. Am. Chem. Soc. 1956, 78, 35533557.

(43) Brauer, D. S.; Karpukhina, N.; Law, R. V.; Hill, R. G. Structure of Fluoride-Containing Bioactive Glasses. J. Mater. Chem. 2009, 19, $5629-5636$

(44) Lockyer, M. W. G.; Holland, D.; Dupree, R. NMR Investigation of the Structure of Some Bioactive and Related Glasses. J. Non-Cryst. Solids 1995, 188, 207-219.

(45) Tilocca, A.; Cormack, A. N. Structural Effects of Phosphorus Inclusion in Bioactive Silicate Glasses. J. Phys. Chem. B 2007, 111, 14256-14264.

(46) Kiani, A.; Lakhkar, N. J.; Salih, V.; Smith, M. E.; Hanna, J. V.; Newport, R. J.; Pickup, D. M.; Knowles, J. C. Titanium-Containing Bioactive Phosphate Glasses. Philos. Trans. R. Soc., A 2012, 370, $1352-1375$.

(47) Xue, X.; Stebbins, J. F. ${ }^{23}$ Na NMR Chemical Shifts and Local $\mathrm{Na}$ Coordination Environments in Silicate Crystals, Melts and Glasses. Phys. Chem. Miner. 1993, 20, 297-307.

(48) Brauer, D. S.; Karpukhina, N.; O’Donnell, M. D.; Law, R. V.; Hill, R. G. Fluoride-Containing Bioactive Glasses: Effect of Glass Design and Structure on Degradation, $\mathrm{PH}$ and Apatite Formation in Simulated Body Fluid. Acta Biomater. 2010, 6, 3275-3282.

(49) Abrahams, I.; Franks, K.; Hawkes, G. E.; Philippou, G.; Knowles, J.; Bodart, P.; Nunes, T. ${ }^{23} \mathrm{Na},{ }^{27} \mathrm{Al}$ and ${ }^{31} \mathrm{P}$ NMR and X-Ray Powder Diffraction Study of $\mathrm{Na} / \mathrm{Ca} / \mathrm{Al}$ Phosphate Glasses and Ceramics. J. Mater. Chem. 1997, 7, 1573-1580.

(50) Brow, R. K.; Kirkpatrick, R. J.; Turner, G. L. The Short Range Structure of Sodium Phosphate Glasses I. MAS NMR Studies. J. NonCryst. Solids 1990, 116, 39-45. 
(51) Prabakar, S.; Wenslow, R. M.; Mueller, K. T. Structural Properties of Sodium Phosphate Glasses from ${ }^{23} \mathrm{Na} \rightarrow{ }^{31} \mathrm{P}$ CrossPolarization NMR. J. Non-Cryst. Solids 2000, 263-264, 82-93.

(52) Fan, C.; Li, Q.; Chu, B.; Lu, G.; Gao, Y.; Xu, L. Silver Binding in Argentiferous Manganese Oxide Minerals Investigated by Synchrotron Radiation X-Ray Absorption Spectroscopy. Phys. Chem. Miner. 2018, 45, 679-693.

(53) Buckley, J. J.; Lee, A. F.; Olivi, L.; Wilson, K. Hydroxyapatite Supported Antibacterial $\mathrm{Ag}_{3} \mathrm{PO}_{4}$ Nanoparticles. J. Mater. Chem. 2010, 20, 8056-8063.

(54) McKeown, D. A.; Gan, H.; Pegg, I. L. Silver Valence and Local Environments in Borosilicate and Calcium Aluminoborate Waste Glasses as Determined from X-Ray Absorption Spectroscopy. J. NonCryst. Solids 2005, 351, 3826-3833.

(55) Masai, H.; Koshimizu, M.; Kawamoto, H.; Ohkubo, T.; Koreeda, A.; Fujii, Y.; Ohara, K.; Ofuchi, H.; Setoyama, H. X-Ray Absorption near-Edge Structure of Ag Cations in Phosphate Glasses for Radiophotoluminescence Applications. J. Ceram. Soc. Japan 2019, 127, 924-930.

(56) Helmholz, L. The Crystal Structure of Silver Phosphate. J. Chem. Phys. 1936, 4, 316-322.

(57) Inman, J. M.; Houde-Walter, S. N.; Greaves, G. N.; Dent, A. J.; Dobson, B. R. Structural Characterisation of Silver Ion Exchange in Alumino-Silicate Glasses. Jpn. J. Appl. Phys. 1993, 32, 667-669.

(58) Ghigna, P.; Muri, M.; Di; Mustarelli, P.; Tomasi, C.; Magistris, A. Local Order of $\mathrm{Ag}$ in $\mathrm{AgI}-\mathrm{Ag}_{2} \mathrm{MoO}_{4}$ Glasses: An EXAFS Study. Solid State Ionics 2000, 136-137, 479-481.

(59) Tordjman, I.; Boudjada, A.; Guitel, J.-C.; Masse, R. Structure de l'hydrogénophosphate d'argent $\mathrm{Ag}_{2} \mathrm{HPO}_{4}$. Acta Crystallogr., Sect. B: Struct. Crystallogr. Cryst. Chem. 1978, 34, 3723-3725.

(60) Sipr, O.; Dalba, G.; Rocca, F. Ordered and Disordered Models of Local Structure around Ag Cations in Silver Borate Glasses Based on X-Ray Absorption near-Edge Structure Spectroscopy. Phys. Rev. B 2004, 69, No. 134201.

(61) Seward, T. M.; Henderson, C. M. B.; Charnock, J. M.; Dobson, B. R. An X-Ray Absorption (EXAFS) Spectroscopic Study of Aquated $\mathrm{Ag}^{+}$in Hydrothermal Solutions to $350^{\circ} \mathrm{C}$. Geochim. Cosmochim. Acta 1996, 60, 2273-2282.

(62) Belharouak, I.; Fargin, E.; Parent, C.; Le Flem, G.; Aouad, H.; Mesnaoui, M.; Maazaz, M. An EXAFS Study of $\mathrm{AgPO}_{3}$ and $\mathrm{AgBaP}_{3} \mathrm{O}_{9}$. Solid State Sci. 1999, 1, 287-300.

(63) Yamaguchi, T.; Johansson, G.; Holmberg, B.; Maeda, M.; Ohtaki, H. The Coordination and Complex Formation of Silver(I) in Aqueous Perchlorate, Nitrate, and Iodide Solutions. Acta Chem. Scand. 1984, 38a, 437-451.

(64) Chapman, K. W.; Chupas, P. J. Pair Distribution Function Analysis of High-Energy X-Ray Scattering Data. In In-Situ Characterization of Heterogeneous Catalysts; Wiley: 2013; pp 147-168.

(65) Takeshi, E.; Billinge, S. J. L. The Method of Total Scattering and Atomic Pair Distribution Function Analysis. In Pergamon Materials Series; Elsevier Ltd: 2012; Vol. 16, pp 55-111.

(66) Hoppe, U.; Kranold, R.; Stachel, D.; Barz, A.; Hannon, A. C. Variation in P-O Bonding in Phosphate Glasses - A Neutron Diffraction Study. Z. Naturforsch., A 2000, 55, 369-380.

(67) Pickup, D. M.; Ahmed, I.; Guerry, P.; Knowles, J. C.; Smith, M. E.; Newport, R. J. The Structure of Phosphate Glass Biomaterials from Neutron Diffraction and ${ }^{31} \mathrm{P}$ Nuclear Magnetic Resonance Data. J. Phys.: Condens. Matter 2007, 19, No. 415116.

(68) Bingham, P. A.; Barney, E. R. Structure of Iron Phosphate Glasses Modified by Alkali and Alkaline Earth Additions: Neutron and X-Ray Diffraction Studies. J. Phys.: Condens. Matter 2012, 24, No. 175403. 